Portland State University

PDXScholar

1977

\title{
Service delivery to deaf persons : a survey and proposal
}

Patrick F. Walsh

Portland State University

Follow this and additional works at: https://pdxscholar.library.pdx.edu/open_access_etds

Part of the Mental and Social Health Commons, and the Social Work Commons

Let us know how access to this document benefits you.

\section{Recommended Citation}

Walsh, Patrick F., "Service delivery to deaf persons : a survey and proposal" (1977). Dissertations and Theses. Paper 1982.

10.15760/etd. 1981

This Thesis is brought to you for free and open access. It has been accepted for inclusion in Dissertations and Theses by an authorized administrator of PDXScholar. For more information, please contact pdxscholar@pdx.edu. 


\section{SERVICE DELIVERY TO DEAF PERSONS:}

A SURVEY AND PROPOSAL

\section{$5 y$}

PATRICK F: WALSH, JR.

A practicum submitted in partial fulfillment of the requirements for the degree of

MASTER OF SOCIAI WORK

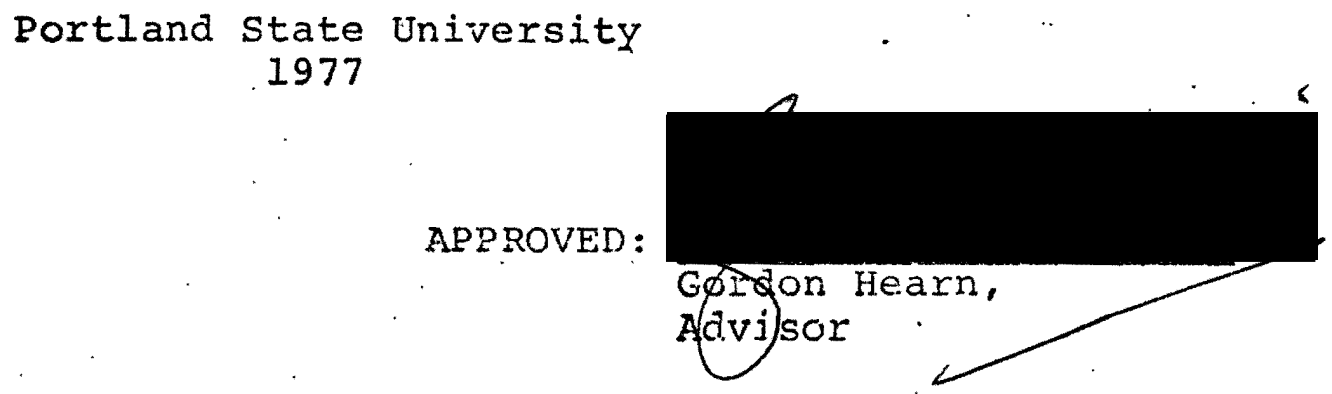


TABLE OF CONTENTS

PAGE

LIST OF TABLES • • • • • • • • • • • • • • • v

LIST OF FIGURES • • • • • • • • • • • • • • • • • • vi

CHAPTER

I FACTORS CONTRIBUTING TO EMOTIONAL PROBLEMS

IN DEAF PERSONS: A SURVEY OF THE

IITERATURE . . . . . . . . . . . . . . I

Introduction . . . . . . . . . . . . 1

Definition of the Problem . . . . . . . 2

Population

Psychological Characteristics

Incidence of Emotional Problems

Factors Contributing to Emotional Problems 9

Framework for Discussion . . . . . . 10

Process of Identification

Entrance Into the School situation.

Beginning Adolescence

Young Adulthood

Service Delivery Problems . . . . . . 36

The "Non-system" System

Recommendations

Personal Conclusion

II SERVICE SYSTEM IDENTIFICATION FOR DEAF YOUTH AND THEIR FAMILIES IN PORTLAND, OREGON:

ORIGINAL RESEARCH . . . . . . . . . 42

Introduction ........... . 42

Methodology . ........... 43

Findings . . . . . . . . . . . 44 
Age, Sex, Hearing Status

Family Composition, Residence

Diagnostic Process

Educational Services

Behavior and Adjustment

Service Delivery Problems

Discussion .......... . . 55

Incidence of Behavior Problems

Service Availability

Future Services

Rersonal Conclusion

III MODELS OF SERVICE DELIVERY TO THE DEAF:

A SURVEY OF THE LITERATURE . . . . . . . 59

Vocational Rehabilitation Model . . . . 59

Personal Conclusion

Mental Health Model . . . . . . . 63

Personal Conclusion

Professional Consultation Model . . . . 65

Personal Conclusion

Information, Referral, Advocacy Model . . 67

Personal Conclusion

Summary . . . . . . . . . . 69

IV SERVICE DELIVERY FOR THE DEAF: A SYSTEMS

APPROACH . . . . . . . . . . . . . .71

Conceptual Framework .......... 73

Development of a Model . . . . . 76

Access Service........... . 80

Coordinating Service... . . . . . 82

A Direction-Intervention Service organization 
SELECTED BIBLIOGRAPHY . . . . . . . . . . . . 88 APPENDICES :

APPENDIX A: IETTER OF INTRODUCTION . . : . . 95 APPENDIX B: PARENT QUESTIONNAIRE FORM . • . . 96 APPENDIX $C$ : CONSENT TO RELEASE OF INFORMATION FORM . . . . . . . . . . 98

APDENDIX D: PARENT INTERVIEW SCHEDULE • • • 99 APPENDIX E: TEACHER QUESTIONNAIRE . . . . . 103 


\section{IIST OF TABLES}

TABLE

PAGE

I Diagnostic Information: Age Range, Mode, and Median by Parent Recollection . . . . . .

II Source of Information About Deafness, by

Parent Recollection . . . . . . . : . .

II Parent Rating of the School as a Resource for

1. Adjustment Problems, by Sex of Child, and

Identification of Behavior Problems . . . .

IV Resources for Dealing with Future Problems,

Identified by Parents . . . . . . . . .

V Referrals Suggested by RPD Staff for Students with Emotional or Behavioral Problems . . 


\section{LIST OF FIGURES}

\section{FIGURE}

PAGE

1 The Systems Universe . • • • • • • • 75

2 The Social Work Domain . . . . . . . 77

3 Direction-Intervention Approach . . . . 79 


\section{CHAPTER I}

FACTORS CONTRIBUTING TO EMOTIONAL PROBLEMS IN

DEAF PERSONS: A SURVEY OF THE LITERATURE

\section{Introduction}

Any disability, whether physical, mental, or emotional, carries with it a multitude of potential handicaps. For the person with a physical problem there are considerations of accessibility, relationships, mental, and emotional adjustment as well as difficulties encountered in employment, recreation, and education. The purpose of this chapter is to look at the ramifications of a hearing disability. More specifically it well investigate the literature relating to the mental and emotional adjustment problems of the deaf. Although educational and vocational services for the deaf are of great importance; strict limitations will define the comprehension of this paper. The concern here is with personal and social adjustment and the developmental structures that constrict that adjustment in some deaf individuals.

Some progress has been made in meeting the most basic needs of deaf persons, but a maze of more complicated and delicate needs are only now being fully studied.

This paper will identify the problems faced by deaf people in terms of social and emotional adjustment, and then 
discuss the research on factors which contribute to the problems. The first section will define deafness, investigate the psychological characteristics of the deaf, and then identify the incidence of mental or emotional problems. The second section will review the literature on factors which contribute to the emotional problems of the deaf. The final section will review the literature on the service system available to the deaf. Throughout this presentation, the writer will summarize with personal conclusions. These summaries will both capsulize the literature and explain the writers value stance.

\section{Definition of the Problem}

Population.

Rather than complicate this presentation with degrees of deafness and decible loss categories, a definition will be brief. The classical distinctions of the conference of Executives of American Schools for the Deaf (1938) adequately identifies the disability of deafness.

1. The deaf: Those in whom the sense of hearing is non-functional for the ordinary purposes of life. This general group is made up of two distinct classes based entirely on the time of the loss of hearing:

(A) The congenitally deaf: Those who were born deaf. (B) The adventitiously deaf: Those who were born with normal hearing but in whom the sense of hearing became non-functional later through illness or accident.

2. The hard of hearing: Those in whom the sense of hearing, although defective, is functional with or without a hearing aid.

The definition of deafness, then, as it is used here, relates 
primarily to the usability of hearing, rather that a quantitative 1oss. In order to fully understand the handicapping condition of deafness, one further distinction needs clarification. Those who are congenitally deaf and those adventitiously deafened before the age of four are usually considered "pre-lingually deaf." since the development of speech patterns is not normally acquired, but has to be taught to the pre-lingually deaf through special training methods, these children stand in the greatest need of services.

There are more than $1,767,000$ deaf people in the United States (Schein and Delk, 1974:16). Over 200,000 of these people were prelingually deafened. Bolton (1976:2) suggests that the total number of deaf people has increased with the population.

The proportion of the United States population who are deaf has remained relatively constant for the last 100 years. Since the population has been increasing at an accelerating rate, so has the number of deaf persons. Furthermore, because of advances in medical science, the proportion of children postlingually deafened (after the age of 4 years) has decreased markedly. More than 96 percent of the deaf children of primary school age today were either born deaf or were deafened before the age of two years (90 percent. were born deaf).

The annual "Directory of Programs and Services" from the American Annals of the Deaf (April 1976:144) records 52,485 students enrolled in the 745 schools and classes included in the directory. The large majority of these students are pre-lingually deaf and therefore stand in need 
of the most assistance in education and in personal adjustment.

Psychological Characteristics.

Both educators and rehabilitation counselors have been concerned through the years about the apparent differences in the adjustment of deaf persons, when compared to those who hear. Although everyone seemed aware of these differences, little scientific knowledge had accrued regarding what Thomas Gallaudet, 160 years ago called "Psychical deafmutism." Edna Levine (1962) attempts to delineate the meaning of this phrase and suggests: "Its main attributes are lags and/or distortions in mental, social, emotional, and scholastic development in the context of normative potentials." (537). It is these more subtle handicapping conditions with which this paper is concerned.

The peculiar situation of the deaf has provided a fertile field for the research and theory building of psychologists since the foundations of the science. Rudolph Pinter is commonly held as the father of psychology of the deaf since he was the first to seriously study the adjustment differences of deaf people. His studies were varied and numerous in the early part of this century. The results however offered little direct assistance to the educators who were so helpful that explanations would be provided. There were often conflicting results, but the first scientific attempt at understanding "psychical deaf- 
mutism," had been undertaken. Perhaps it is a critique of subsequent studies, or perhaps a salute to Pinterr, but his findings provide the basic foundation, even today, of the psychology of deafness.

Numerous research studies have been undertaken since the Pinter Period. In one study (Myklebust, 1960) all ten scales of the Minnesota Multiphasic Personality Inventory were administered to deaf and hard of hearing groups.

Statistical analysis showed that the deaf males were significantly different from the normal on all ten scales. Except for Social Introversion, this difference was in the direction of greater maladjustment... the two most deviant scores were on the scales of Schizophrenia and Hypomania. (140)

Although the results of this study are highly criticized because of the verbal dependency of the MMPI, most other research and observation lend credence to Myklebust's conclusion:

r. it cannot be denied that a hearing loss,
in terms of self-concepts, in ego-functioning
and in psycho-sexual relationships. (Myklebust,
$1960: 145)$.

Berlinsky (1952:49-50) concluded from his review of research on personality and social adjustment that the deaf seem to reach the same level of adjustment as hearing people, but notes that they have more trouble adjusting to their environment, are more ego-centric and less mature in terms of judgement and social competence. Meyerson (1963:143), however, clearly states that his review of the literature implies that" ... deafness is not directly related to 
personality in the sense that it requires a particular kind of adjustment." Not deafness itself, but the environmental restraints caused by it may be responsible for some adjustment differences. These are factors of environment and not something innate in deafness. A more recent study (Schuldt and Schuldt, 1972) considered twenty empirical personality studies of deaf children published since 1950 and concluded that deaf children manifest abnormal personality characteristics and less adequate adjustment when compared to hearing children.

Incidence of Emotional Problems.

Having generally identified the deaf as exhibiting behavior that is more ego-centric, lacking in positive selfconcept and often socially inadequate, other studies have tried to determine the rate at which deaf persons exhibit severe emotional or mental health problems.

Rainier and his associates (1963) undertook a. full: scale census of the deaf population of New York state in the late 1950 's. Their findings indicate that the rate of severe psychiatric disorders among deaf persons was about the same as the rate among the hearing population. With one exception the deaf showed the same amount or less mental and emotional problems, as the general population. A marked increase in the incidence of "problems in living" was noted among the deaf. These problems were shown in an unusually high incidence of crime and other anti-social behavior among 
deaf persons. Among deaf criminals in New York, 60 percent had been convicted of sex-related offenses. Several explanations were suggested for the usually high rate, particular concern was mentioned about the possible lack of adequate role patterning in residential school situations.

In analyzing the records of the Langley Porter Neuropsychiatric Institute in San Francisco, Schlesinger and Meadow (1968) found that from 1965-67 eight percent of the children applying for treatment were hearing-impaired. This compares to an incidence rate for deafness among the population of only one percent. Grinker, (1969:10) reports similar findings at the Illinois state Hospital. Hearing problems were seven times more frequent among state hospital patients than in the general population.

The behavioral and emotional problems of deaf children. have received greater attention in the literature through the years, than have the problems of adults. The incidence of mental health problems among all children is of great concern. The Joint Commission of Mental Health of Children (1970:150) estimates:

"Ten to 12 percent of children and youth have major psychological problems, 2-3 percent suffer from mental illness including psychosis, and another 8-10 percent have serious emotional problems."

Several studies of the deaf school samples have indicated that for deaf children, the incidence of emotional problems is even higher. McKay Vernon (1968) studied a sample of deaf students from the California state school at 
Riverside and reported that 34 percent of his sample were judged to have emotional problems, while 6.3 percent were judged to be psychotic.

In an extensive study of the school population at the Berkeley campus of the California School for the Deaf, teachers identified 31.2 percent of their students as being either mildly or severely disturbed (Meadow and schlesinger, 1971). This study was modeled after a study of the Los Angeles public schools in which only 2.4 percent of the students were identified as severely disturbed. While 7.3 percent of the students in Los Angeles were rated as moderately disturbed, among the deaf this rate rose to 19.6 percent.

The Office of Demographic Studies (1973:17) collected extensive data on nearly 35,000 deaf children during the 1970-71 school year. They report that the most common "additional handicapping condition" noted by teachers was emotional or behavioral problems. The rate for this condition was 95.9 per 1,000 deaf.students.

In another study, the families of almost every deaf child between the ages of 5 and 15 in the Vancouver, B.C. area were interviewed (Freeman, et. al., 1976:396). Among the finding of the study is that "On global ratings, 22.6 percent of the deaf children were judged to have psychiatric disorders of a moderate or severe degree." The method of determining disorders varies, but it does seem apparent that 
deaf children are in greater risk of having emotional and behavioral problems than are normal children.

Personal Conclusions.

The research seems to confirm the suspicion that with the peculiarities observed in deaf personality, the deaf are more likely to be found emotionally and behaviorally deviant. The fact that four of the five studies included here show twice the incidence of behavioral and emotional problems among deaf children, indicates that something is wrong with the environment and support given to the deaf. In order to understand why deaf children have more problems in adjustment, a close investigation of the environment in which deaf children develop is called for. Maladjustment is not a part of deafness, it is a function of the environmental constraints placed on deaf children.

\section{Factors Contributing to Emotional Problems}

Considerable research in recent years has investigated the impact of early childhood deafness on learning and social adjustment. Two primary factors seem to account. for the unusually high rate of social problems among the deaf. Communication difficulty is perhaps the most obvious factor that inhibits normal development of deaf children. The other factor is more subtle. Much of the research has pointed to stress points in the development of deaf children. These stresses have an impact on his personality and his. social development. 
Framework for Discussion.

Attention will be focused here on the literature and research that relates to those factors which make the development patterns for deaf children different from those for normal hearing children. Moores (1973) has noted that more than a hearing loss is involved when deafness is discovered. The entire family is immersed in emotional upheaval, confusion, concern and special services. As Marshall (1974) aptly notes:

From a parent's viewpoint, the diagnosis of a handicap is not the end. It is not even the beginning of the end, but rather the end of the beginning of a long series of life adjustments. $(66$.$) .$

Since the personality development and social adjustment of a child cannot be separated from the environment that surrounds him, the literature will be reviewed following a framework of family stress periods proposed by Moored (1973). He points out that particularly strong emotion is involved in the transition periods in the life of any family. For a family with a deaf child, the stress of these transition periods is amplified.

Four periods seem to be particularly stressful in the family life of a deaf child: (1) the process of identification, (2) the entrance into the school, (3) the beginning of adolescence, and (4) early adulthood. In each transition period, the question of communication arises. The handicap of deafness impedes the communication in the home, in the 
school, on the job and in social relationships. Mindel and. Vernon (1974:59) note that while an average five year old is aware of and can use from five to twenty-six thousand words and has considerable syntactical skill, a deaf child is often fortunate if he can use 200 words, even with early and constant oralism training. Although involved in each stress period the communication factor is critical at the earlier stages of development.

Process of Identification.

The birth of a child into a family is in itself a potential life crisis. It involves a shifting of life styles and role responsibilities for every member of the family. Ross. (1954) identifies some of the meanings that parents give to their idealized, potential child. He may be the product, quite literally, of his mother's labor, a personal achievement. Perhaps he is thought of as a "gift," of the mother to her husband, or to her own mother, or a gift from God and $a$ sign of blessing. Often the child is the completion or maturity statement of the parents, the final factor to make their family normal and acceptable.

Parental Reaction.

In most cases, the parents themselves are the first to suspect that "something is wrong" with their child. Fellendorf and Harrow (1970) in their survey of 260 families with deaf children found that in 70 percent of the cases the parents were the first to suspect a hearing loss. This 
suspicion begins a series of emotional reactions in parents which have been identified as shock-bewilderment-sorrowanger-guilt (Ross, 1964 and Meadow, 1968b). Shock and bewilderment brought on by the unexplained presence of a handicap that parents know nothing about, is usually followed by a real sense of mourning over the loss of their dreams for the ideal child. This sorrow is often followed by anger at their fate, or anger at the child for destroying their dreams. Anger, however, is an unacceptable parental response for most people and thus engenders guilt feelings in the parents. If left unresolved, these feelings of resentment and guilt continue to complicate the developmental environment of the deaf child and the family equilibrium of the parents and other siblings.

\section{Diagnostic Process.}

Once the suspicion has been raised, the parents begin the process of having their fears confirmed. Since deafness is a rare happening, parents report that often they have great difficulty in getting doctors to agree with their suspicions. Parents are cast into a long and confusing chain of referrals from physician to specialists.

In seeking a medical diagnosis parents have certain expectations that are often frustrated by the professionals they contact. Meadow (1968b) identifies the problem as a role discrepancy. While parents seek both medical facts and a sharing in their grief, doctors often know little about 
deafness, can give little definite information, and feel uncomfortable in an affective role. Survey data seem to support this contention. In Meadow's (1968b) study of 33 families with congenitally deaf children, one third said that the doctor denied their suspicion of a hearing impairment and 60 percent of the sample consulted four or more physicians before receiving a definite diagnosis. Fellendorf and Harrow (1970) found that 81 percent of the families in their survey were convinced of the diagnosis after from one to three seperate physicians. Barasch (1968) notes however that parents of hearing impaired children are much more likely than parents of other handicapped children to seek as many as five or more diagnosis. He suggests they are often in a search for a more positive prognosis or a wishful reduction of their child's handicap.

A recent study of nearly every case of chilahood deafness (Freeman, et. al., 1976) found that in 54 percent of the cases for. which detailed histories could be obtained, the family physician was said to have rejected the parental suspicion with, or without, some sort of test. In another 20 percent of the cases the physician was unsure. Half the physicians agreed to a referral for special assessment, but 36 percent refused to refer.

For whatever reason, the diagnostic process is a lengthy and difficult time for parents of a deaf child. Fellendorf (1970) found that 72 percent of the children were diagnosed by 18 months and Freeman (1976) found the average 
age of diagnosis for cases within the Vancouver area was 23.9 months.

Inadeguate Information.

One of the parents expectations of the medical profession is an explanation of the cause of the deafness and its potential consequences. Parents resent the limited time spent by professionals interpreting the diagnosis for them and explaining its impact (Barsch, 1968). In studies with mentally retarded children, zuk (1962) found etiology important to parents since their own anger and guilt are deeply involved in the identification of a handicap in their child.

This need for an explanation is left unsatisfied for most parents of deaf children. Meadow (1968b:303) notes that in her study, a full 80 percent of the parents had no information on the etiology of the deafness. Freeman (1976:393) considered nearly every deaf child in the area, including. those deafened in later childhood, and found that 43.6 percent of the cases were of "unknown cause."

Fellendorf's (1970:54) finding that 49 percent of the families responding to $h$ is survey were not satisfied with the advice and diagnosis they received from specialists is partially related to inadequate etiological explanation. The final activity in the diagnostic process is the deafness. Freeman (1976:393) considered nearly every deaf child in the area, including those deafered in later childhood, and found that 43.6 percent of the cases were of 
"unknown cause."

Fellendorf's (1970:54) finding that 49 percent of the families responding to his survey were not satisfied with the advice and diagnosis they received from specialists if partially related to unadequate etiological explanation.

The final activity in the diagnostic process is the entry into the field of special services. Although the diagnosis of the impairment is made in the medical field, the amelioration and treatment of it is not usually medical (Meadow, 1968b). Referral must be made to multiple services that will be required for the language, education, and emotional development of the child.

In most cases, the doctor was not a source of relevant advice after the diagnosis. Fellendorf (1970:57) found that 37. percent of the respondents to his survey found thei'r best advice after the diagnosis from a local hearing and speech center. Another 17 percent depended on the Alexander Graham Bell Association or its John Tracy Clinic for help and advice. The Tracy Clinic is a kind of correspondence course that provides parents with a program for teaching speech and oralism to very young children. The parents correspond with one staff member who can become a source of help in many area's of parental concern. In Meadow's study (1968b) 90 percent of the families has had some contact with the Tracy clinic, but few actually finished the program. Although most families seem to seek information from the A. G. Bell Association, Moores (1973:119) is concerned 
about the negative impact it can have on some families.

One can only guess how many thousands of families have been harmed by the counseling of well-meaning but misinformed individuals whose advice has really been aimed primarily, not at the healthy development of the deaf child, but rather at the neurotic, selfish needs of parents who want their children, as psychological extensions of themselves, to be "normal," i.e., speaking.

Another source of early help for parents is the preschool training that many deaf children receive. The office of Demographic Studies (1972) reported that during the 1970-71 school year, their survey of programs for the deaf show approximately 10,000 children under six years of age were enrolled in pre-school programs and about half of these parents were receiving some kind of training related to their child's hearing loss.

Moores (1973:21) reports on a study of the differences in parents as a function of their deaf child's pre-school program. One of the findings showed that:

Fathers and mothers of deaf children in oral-only programs believed the primary function of an educational curriculum for hearing-impaired children was to develop speech and speech reading skills. Parents of children in programs utilizing both oral and manual communication, however, believed the primary function was to provide appropriate instruction in academic skills such as reading, language and writing.

Hence, Moore suggests that parents receive advice and attitudes from these pre-school programs that often reflect the prejudice of the teacher or program director rather than what may be in the best interests of the child. Interestingly, Meadow (1968b) notes that 60 percent of the 
children in her study with deaf parents received no preschool training, while only 18 percent of the heraring parents did not participate in the pre-schools.

Child Rearing Practices.

The process of identification cannot be totally

separated from the practices of rearing the child. The final part of this first section will briefly survey the literature. regarding the child rearing practices of parents with handicapped children.

Much of the research dealing with handicapped children and the practices of parents indicate two basic responses: over-protection and unexplained punishment (Mindel and Vernon, 1974:461. Most parents of normal children automaticaliy develop a method of providing discipline and expectations from a composite of memories, ambitions, accomplishments, and comparisons with other siblings and peers, or from societal expectations. For the parent of the handicapped child, these expectations do not always fit.

Within the complex of emotions that involve the parents of a deaf child is the frustration over what to expect from the child. Their child is different, and in some cases cannot' be expected to measure up to the requirements placed on normal children. The parents themselves usually sift out a set of expectations that take into account the handicap and the special needs of their child without professional assistance. Ross (1964:129) indicates that these expectations can and should be set, but sometimes this process is 
complicated by the unresolved emotional problems of the parents.

Largely because of such inappropriate emotions as guilt and pity toward the handicapped child they feel constrained in enforcing discipline in the same manner in which they would for an unimpaired child.

Unless the emotional reaction to the diagnosis of impairment has been integrated and resolved by the parents, further complications appear throughout the parent-child relationship. Parents express their guilt, if it has not been resolved, in three typical responses: a fervor for prescription techniques that becomes almost punitive; a sliding from over-protection to out-right rejection; or a commitment to self-sacrifice and martyrdom (Meadow, 1968b). The impact of these responses can be devastating not only on the child but to the entire family (Ross, 1964).

Schlesinger and Meadow (1972c) compared the childparent relationship of forty pre-school deaf children against hearing pre-schoolers. In observations of the mother-child reactions, the mothers of deaf children were more intrusive, less flexible and less encouraging than the mothers of hearing children. Information from interviews of child-rearing practices indicated:

Almost two-thirds of the mothers with deaf children reported using control of the environment to protect their children from (street accidents), compared to only one-quarter of the mothers of hearing children. . It is difficult to say where reality. stops and "over-protection" begins. Fully 20 percent of the mothers with hearing children report some kind of "close call" with cars and children, 
compared to only 3 percent of the mothers with deaf children (103).

The study in Vancouver (Freeman, et. al., 1976) sustantiates these findings with a significant difference noted between parents of deaf child and normal children in terms of restricting and environment.

The communication factor is important to note at this point. Hans Furth (1966), a linguist who has studied the learning ability of deaf children notes that because of the lack of meaningful communication with their environment, deaf children are deprived of learning stimulation in much the same way that the poor or minority groups are deprived. Schlesinger and Meadow (1972c) show that this learning deprivation includes learning social skills as well as academic material. In their studies, deaf children with deaf parents (where manual communication is learned naturally) scored higher in nearly every academic and social adjustment factor. However, the research indicates that parents of deaf children as a rule seem to be over-protective to a degree beyond the restrictions necessitated by the handicap.

Personal Conclusion.

This section has indicated that the birth of a deaf child is a traumatic experience for a family. In addition to the initial shock and bewilderment, the family must rearrange priorities and then begin the frustrating process of diagnosis and prescription. Resentment and guilt are not 
uncommon reactions to the disillusionment, emotion, time, and money that must be invested in the diagnosis and treatment of the handicapped child. Professionals offer some technical expertise, but most parents either resolve their own emotional problems, or have them complicated by poor advice, then to be expressed at some later stage in their child's development.

There are measureable differences in the early life of the deaf child and in the relationship he enjoys with his parents. The maze of responsibilities and hardships placed on the parents combined with emotional stress and lack of communication all impact the parenting process with deaf children.

It is not possible to draw a direct relationship between any one factor noted here and the emotional problems of deaf children but normal development seems clearly hampered by these blockages to a full parent-child relationship. The conflicting advice, lack of adequate information and lack of affective support through this system indicate the need for special direction and follow along services to assist in the medical and parenting process with deaf children.

Entrance Into the School Situation.

- The second major step in the socialization of any child, is his entrance into school. For the parent of the deaf child, this is an especially stressful movement since a 
number of educational decisions have to be made. Two major teaching methods are employed in schoolsfor the deaf: the strict oral approach and the total communication approach. In addition to a decision on method, parents must be concerned with the setting in which the education will take place: Residential school, a day school for deaf students, or an integrated regular classroom are options in some areas. A survey by Craig and others $(1976: 63)$ indicates that 30.16 percent of the residential schools, 65.45 percent of the day schools and 73.60 percent of. the day classes in regular schools provided some kind of integration program during the 1974-75 school year. More and more children have been included in integration and "mainstreaming" efforts in recent years, especially since the 1975 Education for All Handicapped Children Act, but often the schools make the determination on who will be integrated.

Two principle factors contribute to the stress for families at this stage: the method of instruction which provide the academic basis for future life, and the social environment offered by each school setting. This section will investigate the literature as it relates to these factors.

Communication Method.

Probably the greatest volume of research in the field of deafness has related to the educational deficiency of deaf students. No single type of school setting can be held fully responsible, but studies have documented consistent 
educational retardation among deaf children. Mindel and Vernon (1974:88-93) have gathered together a number of recent studies.

In the most extensive current survey of the education achievement (Boatner, 1965 and McClure, 1966) which included ninety-three percent of the deaf students sixteen years and older in the United States, only five percent of the students achieved at a tenth grade level or better. Most of this five percent were hard of hearing or adventitiously deafened. Sixty percent were at grade level 5.3 or below and thirty percent were functionally illiterate (94).

Among the many studies of this problem, one by the Advisory Committee on Education of the Deaf (Babbige, 1965) found the problem seemed to increase in the later years.

At no age was the median grade average as high as the seventh grade despite the fact that the bulk - of those included were at least high school leaving age (22).

Traditionally the low achievement of deaf children has been considered a part of the handicap and a function of being deaf. However recent comparative studies have indicated that communication method and restricted educational opportunities limit the educational achievement of deaf children.

In their comparison of students in residential schools, who use total communication, with students in day school using the oral-only method, Schlesinger and Meadow (1972c) found that day students scored higher in math, reading, and general grade level than did residential students. However, those day students who had been exposed to Total Communication were nearly a grade level higher than those in residential 
schools. Day students in strictly oral programs were less markedly above residential students.

A series of research projects have been conducted to measure the achievement of children who use manual communication from early childhood when measured against children who are taught by the oral-only method. The manual communication group has been composed almost exclusively of deaf children of deaf parents. This relatively small group (less than ten percent of the prelingually deaf children in the country) provides a fascinating control group to measure the innate influence of deafness and impact of early communication.

Mindel and Vernon (1974:75-79) note many of these studies in their plea for greater acceptance of total. communication. The majority of the nine studies they cite were aimed at the academic and language proficiency of the subjects, but several looked at some areas of personal adjustment. Their synopsis shows that fax from retarding academic and social development, early manual training enhances most phases of development. Only in one study (Quigley and Frisina, 1961) and then only in speech did the oral group score higher than the manual group. Social Environment.

In addition to the educational disadvantages facing the deaf child and the stress that causes his family, there is a social consideration which must be taken into account as well. There are advantages and disadvantages to both the residential setting and the day school placement. 
Although mainstreaming is a growing concept, for at least half the deaf students in the country, the residential school is best or only option (Bolton, 1976). To a great extent, this placement at age three or four means that the family is at least partially replaced by the institution as the socializing agent for the deaf child.

Most studies of residential schools have indicated that institutionalization has a negative impact on students. Barker (1953:206) in his review of the research concludes that the residential schools "are not optimal environments for the development of social maturity." The one exception most often cited in the literature is a study by Quigley and Frisina (1961) which found no evidence that living in an institution had a detrimental effect on deaf teenagers either academically or socially. Most residential schools have become aware in recent years of the need to provide a closer association with families and more opportunity to experience the community outside the institution and have undertaken special programs (Youngs, 1976).

Schlesinger and Meadow (1972c) compared the adjustment of three groups of deaf students: residential students with deaf parents (group 1); residential students with hearing parents (group 2); and day school students with hearing parents (group 3). Their data indicated that group 1, the children of deaf parents, scored higher in almost all indicators of social adjustment than did their peers with hearing parents. They did find, however, that the day 
students rated significantly higher in appropriate sex role identification than did either group in the residential school. Day students (group 3) scored almost the same as group 1 in maturity and responsibility and were rated higher in all indicators than residential students with hearing parents.

It appears from this data that deaf children with hearing parents have an advantage in terms of social adjustment if they stay at home with their parents rather than attending a residential school. Further investigation of the data indicated that family climate was a strong factor in the adjustment scenario. Family climate affected day students to a greater degree than it did residential students and was a more significant factor in the development of self-image among children with hearing parents than among those whose parents were deaf. (Meadow, 1969, Schlesinger and Meadow, 1972c:136).

The residential environment is necessarily somewhat restricted in terms of family life modeling. What might be considered family chores are provided by maintenance staff; privacy and leisure time are less available, security and supervision are maximized, and community contact is limited. The great advantage of the institution however is that social contact with other deaf students is constant. There is an opportunity to excel among equals and to build close friendships.

If the day school environment has more positive results 
in terms of social adjustment, it must be considered that family climate is a strong variable for the day student, and social relationships will be less constant. Meadow (1969) conducted a survey of matched pairs of deaf children with hearing parents and with deaf parents in California. She found that the group with deaf parents scored consistently higher on the Vineland Self-image' Scale than did the group with hearing parents. She contributes this, at least partially, to the existence of an early system of meaningful communication.

Among those children. with hearing parents, the ability to communicate took on added significance.

Communication ability has the strongest effect on. the self-image of children with hearing parents. Only 21 percent of the children with hearing parents and below average communication skills scored high the self-image test, compared to 56 percent of the children with hearing parents whose communication ability was above average. (Among the children with deaf parents about 60 percent scored high in self-image, regardless of rating for communication.). (Meadow, 1969:436).

In studies of the social relationships of integrated hearing impaired children (not profoundly deaf), Force (1956) found that hearing-impaired children were picked less often as playmates than, any other handicapped group except cerebral palsied children. He suggests that the presence of a visible handicap (a hearing aid) causes aversion in the other children: Elser (1959) makes the opposite conclusion. He found that among 9 to 12 year olds, those with the least severe impairment (those without hearing aids) were the least 
acceptable. He notes, though, that no impaired student was as acceptable as normal peers.

Kennedy and Bruininks (1974). studied 15 fully integrated hearing impaired students and found that they rated significantly higher in popularity than their normal peers. Although these finding are different, the bulk of the research (Shears and Jensema, 1969) shows that handicapped children will not be accepted as easily as normal children.

\section{Personal Conclusions.}

The decision on a school placement brings emotional stress on the family and impacts the future development of the child in both his academic learning and his social adjustment. The parents often receive conflicting counsel about methods of. instruction, programs and situations.

In the residential school their child will perhaps receive a less adequate education, but will have the advantage of close friendships and deaf role models. In the day program, the child may receive a better education, but will be stigmatized by his speaking ability, have less friends and more competition. The family climate and communication within the family is of greater importance if the child is in a day school. If he is taught in residence the family may lose contact. Although these problems present themselves in early childhood, it is at school entrance that the family and the deaf child must face professional conflicts surrounding deafness. 
Beginning. Adolescence.

At the onset of adolscence, the deaf child begins to become an adult and he and his family face the third stage of emotional tension. Whether he is being educated outside of the home, or in a day school, adolescence brings a tide of new realizations and concerns for both child and family. The deaf person must find a new role in the family, he is no longer a child, but not yet an adult. He also becomes more aware of himself and is expected to develop a social life and begin dating. Finally, at this stage both parents and child become aware of the employment possibilities of a deaf person and begin to be concerned about the future.

\section{Family Role.}

Much of the literature notes that at adolescence, the child begins to express his own feelings and has to find a new role in the family. If the parents have not resolved their seeking for normalcy, they are struck at this stage that time has run out and may be overcome with grief again. Because they were not helped to work through the conflict when the child was young, the realization at this stage unleashes a tide of frustration, resentment and hostility which is vented on the system of professionals that has misguided them. (Mindel and Vernon, 1972).

A part of assuming anew family role is being accepted as a teenager and receiving recognition from his parents. The question of child-rearing re-enters at this stage when a new set of expectations must be met. The deaf teenager 
may be immature for his age as Moores (1972) notes, but parents are often unaware of the reasons for this immaturity and fail to use this situation to help him in developing his full potential. They may have forgotten their own overprotectiveness which has sheltered the deaf teenager from the very experiences that bring about maturity. Ross (1964) notes that this is a difficult time for the family of any handicapped child. Although his handicap may limit his abilities in some areas, they have not limited his right to have an opinion, make a judgement or be consulted on family matters. It is an important part of developmental expectation to include experiences that will lead to the child's full adult potential.

Communication is a factor in the sometimes difficult role adjustment for the deaf teenager. Research has indicated that without adequate communication social norms and expectation are not incorporated in the behavior of deaf individuals. Mindel and Vernon (1974:100) note that the educational retardation of most deaf children combined with "impoverishment in general knowledge of social codes born of the limitations in communication resulted in an incapacitating naivete" in a group studied in Chicago. Further evidence of this naivete is indicated by schlesinger and Meadow (1972c). Even if normal development can be achieved for some deaf children, there will still be problems with communication. Natural learning, role modeling, punishment and management can occur without verbal language but for the 
deaf child communication is necessary.

Although his mental functions are developing, his language is not. Failure to develop the necessary accompanying and relevant language of his life patterns leads to progressive isolation from his family. The resulting frustration over the issue rises at times to intolerable heights both for him and his family. (Mindel and Vernon, 1974:100).

The lack of language ability makes the communication of developing responsibilities difficult, if possible at all, for most deaf children.

\section{Social Lifa.}

It has been previously stated that deaf children in regular schools are not as likely to be chosen as friends. Although a problem for the child, this becomes a tragedy for an adolescent. There are few opportunities for these children to spend time with other deaf teenagers because they are dispersed through-out the city.

For the residential school student there are plenty of opportunities to have friends, but sometimes severe restrictions are placed on boy-girl relationships and dating.

Evans (1975) tested a group of students in a residential school and compared them to a hearing sample the same age.

More than twice as many deaf (24 percent) as hearing teens (1I percent) stated that they had never dated. On a test of dating knowledge 43.8 percent of the deaf respondents missed more than half the dating items compared to only 7.9 percent of the hearing teens (549).

Evan's (1975) study has been highly criticized by educators (Youngs, 1975) and others because of the time lag between his data collection and reporting. In recent years 
residential schools have made considerable changes in programs and policies. However, control and management problems faced by school personnel remain as a real restriction. Because they serve "in loco parentis" they must protect themselves from the "consequences". of unrestricted relationships.

\section{Vocational Preparation.}

Another area of concern for both parents and child in the teenage years is career planning and wondering about vocational potential. At adolescence the parents become realistic about the employment horizons for their deaf child and seek information on vocational preparation or postsecondary training.

The deaf traditionally have been employed below their potential (Schein and Delk, 1974, Schein, 1968), and parents. begin to realize that preparation for a job is a more complicated task for their deaf teenager. Bolton (1975) reports that

Many deaf youth do not have the necessary developmental experiences and therefore require remedial preparation. . Lerman and Guilfoyle (1970) compared the prevocational development of 340 deaf adolescents aged 12 to 20 and 85 normally hearing youth who were brothers and sisters of the deaf subjects. The hearing youth were found to be vocationally more mature; they preferred jobs of higher socioeconomic status, they expressed greater consistency of vocational interests, and they possessed more vocational information. (12).

Faced with the realization that their deaf teenager is not as mature vocationally, parents often seek help from the 
schools, community colleges, or vocational rehabilitation. They have come to a transition time and are facéd with a new array of service needs in the field of vocational preparation. Personal Conclusions.

Adolescence is a time of transition for any child. For the parents of deaf children it is a time of particular emotional stress since the wish for normalcy has not been realized. The hopes for improvement in speech seem dashed and the immaturity of their deaf child causes concern about social activities and vocational placement.

The inadequacy of the school situation may become critical at this stage when dating is encouraged by parents, but friends are scarce for the integrated student and. structures constrict the residential student. When faced with employment, basic skills become more important than speech and deaf children are still below the seventh grade in academic achievement. The provision of social services is restricted primarily to teachers and school counselors. Communication and lack of understanding block deaf teers and their parents from many other professional helpers.

Young Adulthood.

All the factors considered previously, the patterns of child rearing, the educational and social restrictions on deaf. children, the communication difficulties and parental reactions, all come together in the final point of family stress, the entrance into adult life. Moores (1973) suggests 
that although data is sparce, this step is probably the most traumatic for the deaf individual and his family. parents typically see themselves reflected in their adult children and look for maximum adjustment, a happy family, and a good job. The differences in maturity and employment options frustrate their desire for the best posible life for their deaf son or daughter.

- Parents of deaf children are typically more concerned about the adjustment of their deaf child. They are often involved in his life for a longer period, serving as a resource in the community, a day care assistant with his children, and an information source.

For the deaf person, he may become fully aware, at this stage of the factor that sets him apart from the "normal" world. At this time when he moves out into the world, the full impact of his stigma is realized.

\section{Stigma of Deafness.}

In his classic work on stigma, Goffman (1963:5) notes that whether stigma is based in a physical, character or tribal malady

- . an individual who might have been easily received in ordinary social intercourse poses a threat that can obtrude itself upon attention and turn those of us whom he meets away from him, breaking the claim his other attributes have upon us.

Certainly the communication problems of the deaf individual make what is at first an invisible handicap, very visible. The aversion that accompanies the stigma is experienced by every deaf person. The deaf child has been aware of 
his difference before his movement into the world, but has often been buffered by the residential school, or the protection of his parents and family. Schlesinger and Meadow (1972c:141) found the most extreme difference in the three groups they compared was in the area of adjustment to deafness.

Students rated highest in the dimension by their caretakers are the residential students of deaf parents ( 80 percent rated above the median). Intermediate in ranking is Group 2, resident students with hearing parents ( 50 percent are rated above the median). In contrast only 32 percent of the day school students were rated above the median.

In another study Meadow (1969) found that comminication ability in younger children was the strongest factor in development of a positive self-image among deaf children with hearing parents.

It is not surprising that those. students who have been in the most direct contact with the hearing world would be least accepting of their difference.

Schroedel and Schiff (1972:66) note that contrary to what might be thought, teachers of deaf children and mothers of deaf children have been shown to have no more favorable attitude toward deafness than teachers and mothers of normal children.

A particularly important point regarding the mental health and development of deaf persons is what Goffman (1963) calls the "pivotal fact" of stigma. Stigma is a sociological phenomenon and as such the individual who is himself 
stigmatized holds the same beliefs about identity as the rest of society. The way the deaf individual is reacted to, is the way he will react to himself.

Schroedel and Schiff (1972) report on a number of studies related to the attitude toward deafness in both hearing and deaf persons. Among the conclusions they offer is that:

The significantly more negative responses of deaf subjects. . . support the notion that deaf persons hold negative attitudes towards deaf persons or deafness, or that they believe they are rejected more than they actually are, or both. (64).

The attitudes that the deaf young adult experiences in his parents, his community and himself cause him to seek particular adjustment styles in adult life.

Adjustment Patterns.

Considerable literature is available about the "deaf community" in the United States (Schein, 1968, Schein and Delk, 1974) but less is known about the deaf students who choose not to identify with the deaf.

Marvin Garretson (1969) has identified three typical adjustment patterns for deaf young people. Forty percent will "withdraw from hearing society" into an exclusively deaf community where self-concept can flourish, their communication will be unchallenged and they can excel and lead. At the other end of the spectrum are the 5 to 10 percent who seek to be normal and try to "pass" in the hearing world. They exclude the deaf community, but often do not find acceptance with hearing friends. The rejection by 
hearing people for this group can and often does lead to considerable psychological and personality problems. The other 40 percent are "those young people. who believe they have learned to accept the realities of deafness in a hearing society" and move easily between the greater society and the deaf community.

\section{Personal Conclusions.}

At young adulthood; the deaf student and his parents must face the world "head on." The stigma of deafness can not be modified by special schools or family supports. It cannot be denied that the child is deaf and will relate to others in different way. The young adult may have already decided on the community in which he will live, but the parents may need counsel in accepting the social differences which deafness may necessitate.

Those who choose to identify within the deaf community will continue to need special assistance when dealing with the hearing world. Although social contacts are abundant professional service may be inadequate. For those who choose to integrate with the hearing world, the chance of personality adjustment problems increases and the need for support services is more urgent.

\section{Service Delivery Problems}

This final section will briefly identify some of the service system problems presented in the literature. Throughout the preceding material, problems have been noted and the 
breakdowns of delivery networks have been alluded. The purpose here is to point out those areas where research has been specifically directed at the delivery system for deaf children and their families.

Considering the impairments to social functioning and the family stress periods that have been discussed in the literature, it is somewhat surprising that the service system has received little comprehensive attention. There have been recommendations for education. There have been specific changes proposed for improving vocational rehabilitation service, continuing education or the diagnostic process, but seldom has the entire network of services been studied.

The "Non-system" System.

In the early 1970's the Department of Health, Education and Welfare contracted with the Rand Corporation to undertake an intensive investigation of the delivery of service to handicapped children (Kakalik, et. al., 1974). The study found that the system was hardly a system at all. It suffered from gross inequities, gaps in service, insufficient information, inadequate or deficient controls, and insufficient resources. At the base of the problem, however, was not so much a lack of resources for services but an almost total

lack of direction for those resources.

Even if a full range of service is available. . the absense of an effective local direction service may cause gaps in the mix of needed services a child receives. Gaps may also result from the present institutional emphasis on single types of services. Many services, usually the underdeveloped ones, are not the prime responsibility of any one agency. (15). 
Many of the difficulties that have been mentioned regarding the stressful situation in which parents attempt to find services, are a function of this lack of direction in service delivery. The identification process is fragmented, the counsel available on various methods of instruction and school situations is conflicting and prejudiced. The availability of vocational services and mental health services is scattered and incomplete. Any coordination of specialties is seldom even attempted.

Alfred Kahn's (1973) appraisal of the service delivery system in social services of the United States is particularly applicable to the network available to the deaf and their families. Under the present policy in this country, human services are delivered in a residual, case-by-case approach. Service is offered only in a time of crisis and continuity or follow-up are neither sought nor accepted.

Recommendations.

Chough (1973) suggests a total overhaul of the delivery. system is necessary if adequate service is to be given to deaf persons. He recommends some of the sweeping strategies of community organizing (Frosser, 1973), including institutional change, deaf power movements and implementation of a market mechanism (Rivlin, 197i).

In terms of strictly diagnostic services, Marshall (et. al., 1974) suggests that an approach must include a comprehensive assessment of the disability and the formulation 
of a workable treatment strategy. The review looks at several models for meeting these requirements, but notes that the "yellow pages approach" which now exists is clearly inadequate. Of particular concern in the identification process are according to Marshall: direction and referral, which is handled by almost no one; prevention, which is grossly inadequate; identification, which depends of the sensitivity of the medical profession; and counseling and coordination which requires the cooperation of various competing professionals.

Schlesinger and Meadow (1972d) make similar recommendations for the development of a comprehensive community mental health program for the deaf. Primary, secondary, and tertiary prevention must be included along with treatment in a model program. The prevention must include treatment of parents and families, collaboration with schools and other professionals, consultation, research, and community organization and awareness.

In Freeman's (et. al., 1976) study of families with deaf children, parents recommended similar services as being sorely needed in the service system.

Nineteen percent (of the parents) suggested more help and support around the time of diagnosis; 12. percent would have liked to have had earlier contact with other parents and better pre-schools; 10 percent wanted a reduction in the stress caused by the educational controversy; and 10 percent wanted parents to be presented with alternatives at. the outset. .

Although not a product of research primarily related to 
the deaf, Chough (1974) finds a close relationship between the criticism of the mental health system and the system for serving the deaf. The Joint Commission on Mental Health of Children (19.70) points out that the mental health system tends to be: (I) oriented to helping professionals keep their jobs than meeting service need; (2) oriented to remedial and crisis services rather than prevention; (3) illcoordinated and serving only a small fraction of the population in need; (4) serving mainly those clients who are likely to succeed rather than those in greatest need; and (5) highly traditional and conservative.

Personal Conclusions.

The previous exposition of the factors contributing to the stress in families with deaf children, seems to bear out the concerns of these studies of the service system. The delivery of social services to the deaf and their families is grossly inadequate and requires a thorough reorganization. Perhaps the most fitting conclusion has been offered by the Rand Study

Insufficiency of resources is a major problem, but higher funding alone will not solve the basic problems that we find pervading nearly all aspects of the system: complexity, lack of control and disorganization. The system currently delivering services to handicapped youth defies efficient and effective operation. . (Kakalik, et. al., 1974:15).

It is only through the provision of comprehensive assistance to families and deaf persons that the high incidence of emotional and mental difficulties among the deaf can be. 
reduced. Many services are available, but no system exists which can inform, counsel, and direct deaf people or parents of deaf children through the maze of services, needs, and emotional conflicts. 
CHAPTER II

\section{SERVICE SYSTEM IDENTIFICATION FOR DEAF YOUTH AND THEIR FAMILIES IN PORTLAND, OREGON : ORIGINAL RESEARCH}

\section{Introduction}

The literature indicates that personal and system problems confront deaf youth and their families. To test these trends in a local situation, a survey was developed to identify the needs and service availability for families with deaf youth in Portland, Oregon. The purpose of this study was to identify the existing needs and the existing system through which parents and deaf youth find service.

It was determined. that three types of information were required to identify and measure the availability of services to families with deaf children. Since the research indicates a need for emotional support and information at the time of diagnosis, parents would be asked to recall the process of identification. Secondly, parents would be asked to identify the needs and services used at the present time. Finally, information would be needed on where parents expect to seek out services in the future.

In Oregon, educational programming for deaf children and youth is coordinated by regional centers in Medford, 
Eugene, Salem, and Portland. Through these regional centers, the state contracts educational services to school districts. Portland is the largest program serving 303 deaf students from offices of the Portland Public School District and contracting services for neighboring suburban districts.

\section{Methodology}

Through discussions with the Portland Regional Program for the Deaf (RPD) staff, it was decided that parents of high school students would have required and/or sought out a wider variety of services than would parents of younger children. Through the years support services may have been needed and awareness of future needs would be growing.

Since personal information was sought, the privacy of both parents and students had to be assured. A preliminary questionnaire (Appendix B) and a letter of introduction (Appendix A) were prepared and mailed with return postage to every family of a high school student registered with the Portland RPD (67 families) in November, 1976. This initial questionnaire sought information about behavioral and emotional problems among the deaf youth and some indication of adjustment patterns. If the parents chose to participate in the study, they completed the "Consent to Release of Information" form (Appendix C) and were scheduled for an interview in their home.

Thirty-one (31) parents returned the questionnaire $(46$ percent), but only 22 (32.8 percent of those mailed) could be 
contacted for interviews. These twenty-two families constituted the sample for the study. Home interviews were conducted for an average of two hours by one researcher from January through March, 1977. An open-ended interview followed the structured format presented in Appendix D. Information was gathered on problems in access, quality, and comprehension of services as well as on additional problems faced by deaf teens and their families from the parent's perspective.

In order to further investigate the services ard referrals offered by the school, a survey was prepared and distributed to 15 teachers and support personnel employed by the RPD. This questionnaire (Appendix E) asked school personnel to identify those students under study whose "behavior requires a disproportionate amount of the teacher's time," and the interventions they had attempted with those students. Six of the RPD staff (40 percent) returned the questionnaire. Only. two were resource room teachers and the others were supervisors, vocational counselors, or other support staff. The respondents had been involved in the RPD for from 2 to 15 years with a mean involvement of 7.4 years.

\section{Findings}

Age, Sex, Hearing Status.

The age range of the students considered in the study was from 14 to 19 years of age with a mode age of 16 and a median of 16.41 years. The parents of seven girls $(31.8$ percent of the sample) and fifteen boys were interviewed. 
As rated by their parents, 77.3 percent (17) of the students had a "profound hearing loss," while four were rated "severe" and one "moderate." In terms of speaking ability, 12 (54.5 percent) were rated as "easily underștood," seven parents said that only phrases were understandable and two said that only sounds were spoken. Fifty-nine percent of the sample, 13 students could use and understand manual communication and nine were completely oral. In nine families, other members could communicate manually with the deaf child.

Family Composition and Residence.

In 63.7 percent of the cases (14) the hearing-impaired child was living with both natural or adoptive parents. Three mothers were remarried, three were separated or divorced and two children were in foster care. In all cases of foster care or adoption, the hearing-impaired child was placed in the present family before the age of five years.

There were no "only children" among the sample. "Thirtysix percent (18) of the students had one other sibling and the same number (18) had two other sibiings. The two largest families reported five children in addition to the one who was deaf. In only four cases ( 18.2 percent) there was another hearing-impaired child in the family and only one parent was hearing-impaired.

Almost half (10) of the families resided within school District Number 1 in the City of Portland. An equal number (10) lived in suburban areas surrounding portland and two 
families lived in rural areas more than 15 miles from Portland.

Diagnostic Process.

Parents were asked to remember as best they could the services they needed and/or received at the time their child was identified as deaf. Table 1 presents the average time frame within which this diagnosis occurred.

\section{TABLE I.}

DIAGNOSTIC INFORMATION: AGE RANGE, MODE, AND MEDIAN BY PARENT RECOLLECTING $(\mathrm{N}=21)$ *

Range : Mode Median

Age at Suspicion

6 wks. - 18 mos. 6 mos. 8.92 mos.

Age at Diagnosis

8 mos. - 5 yrs. 18 mos. 21.0 mos.

Time Lag

1 mo. - 30 mos. 10/13/30 11.45 mos.

No. Diagnostic Visits

2 - 5 visits 3 visits 2.9 visits

only 21 responses are considered, since one child was not suspected by the parents and was identified through hearing screening in school at age 5 .

When asked where they received assistance in dealing.

with the emotional upset of the diagnosis, 10 ( 45.5 percent) said they received "no help." of the parents who reported receiving help, the majority (58 percent of those who got help) found the best support from hearing and speech centers, other parents, schools or the John Tracy Clinic. Seventyseven percent (17) of the sample reported some contact. with the Tracy Clinic or the Alexander Graham Bell Association. 
The same number of parents enrolled their child in some kind of pre-school program.

In seeking out information about deafness and other needs, Table II shows that the Tracy Clinic was considered the best source of advice by half the parents. .

\section{TABLE II}

SOURCE OF INFORMATION ABOUT DEAFNESS, BY PARENT RECOLLECTION

\begin{tabular}{lc}
\multicolumn{1}{c}{ Source } & 壬 \\
A.G. Bell Assn./Tracy Clinic & $.11^{*}$ \\
Hearing \& Speech Ctr. & 7 \\
Schools & 5 \\
Other Parents, Agency & 7 \\
No Information Available & 3 \\
No Need for Information & 1
\end{tabular}

* Some respondents listed more than one source of information.

Most parents felt a great need for "someone to talk with" about their child's development, but noted in most cases that pre-school teachers or other parents were the only "experts" available to them. A number of parents specifically mentioned a school visitation experience arranged for parents involved with the Portland Center for Hearing and speech which afforded. visits to each of the three school settings in oregon. This was the only occasion in which parents felt they received a full explanation of the various options for education of 
their child.

Educational Service.

Although the intent of this study was not to evaluate the educational program offered by RPD, several questions related to the school situation in order to identify service needs and utilization during the school years. All the students considered in the study were currently enrolled in a high school through the RPD. Ten ( 45.5 percent) of the stidents were placed in an oral program in a regular high school with assistance from a "resource room" with a teacher who was trained to assist the deaf. Six $(27.3$ percent $)$ of the sample were in Total Communication resource room programs in two regular high schools and the remaining six were fully. integrated into their neighborhood school with itinerate services from the RPD less than two hours per day.

More than half the students ( 54.5 percent) had received the majority of their grade school education in the RPD. Three attended Tucker-Maxon oral School (a private school in Portland) and two were in the state school for the Deaf in Salem. The remaining five students either moved into oregon recently (3) or attended a number of grade school programs. In determining the amount of assistance the school provides for parents, the frequency of contact with the RPD staff during high school was asked. The responses point out that parents feel they contact school personnel more often than the school contacts them. Forty-five percent (10) of. 
the parents said the RPD staff had contacted them less than once a year. Five had never been contacted. However both parent- and school-initiated contacts deaf with generally the same problems as reported by the parents, with the school more concerned about behavior ( 9 to 6 ) and parents more concerned about adjustment ( 6 to 3 ).

When asked if they were satisfied, overall, with the education their child was offered by the RPD, half the parents (11) said "yes." Only three (3) parents answered negatively, and the eight (8) others ( 36.3 percent) had mixed reactions about the quality of educational service. The most frequent criticisms noted by parents was the lack of social activity (4) and the lack of cooperation with parents (3). Two parents in each case noted: their child was not learning but was being "passed along"; the RPD was prejudiced against the total communication approach; and that the speech therapy in high school was inadequate.

Behavior and Adjustment.

From the several questions relating to the adjustment, maturity or behavior of their teenager, parent responses indicated that 13 (59.I percent) of the teenagers were well adjusted and 9 were not well adjusted. Seven of the parents who saw adjustment difficulties also identified their child as having behavior problems, but 6 other parents saw behavior problems even though they felt their child was reasonably well adjusted. 
When parent responses are broken down by the child's sex, boys are identified far more often as having both adjustment and behavior problems. Of the 15 boys in the study, 8 (53 percent) were said to have adjustment problems and 11 (73 percent) behavior problems. Among girls, however, the parents saw adjustment problems in only one case and behavior problems in only two cases (28 percent).

Teachers and support staff of the RPD were also asked to identify students with behavioral problems (i.e., "exhibiting behavior that requires a disproportionate amount of the teacher's time"). They felt that 9 (40.9 percent) of the students included in the study had behavioral problems. In six cases the school personnel and parents agreed that the student had behavior problems. However, school personnel did not share the concern over the behavior of four students identified as problemed by their parents, and added three students whose parents felt they had no behavior problem. After determining some incidence of behavioral and adjustment problems, parents were asked to identify where they had received assistance or counsel in dealing with these problems. Iess than half ( 45.4 percent) felt the school personnel had been helpful. Table III presents the responses of parents regarding help from the school. The parents of children with behavior problems find the school slightly more helpful than do those parents whose children do not exhibit behavior problems. If the school has also identified 
the student as problemed, most parents found the intervention helpful, but 33 percent did not. The parents of girls saw the school as less helpful than did parents of the boys.

\section{TABLE III}

PARENT RATING OF THE SCHOOL AS A RESOURCE FOR ADJUSTMENT PROBLEMS; BY SEX OF CHILD AND IDENTIFICATION OF BEHAVIOR PROBLEMS

$\begin{array}{lrrrr} & \text { N } & \frac{\text { School Helpful? }}{\text { YES }} \\ \text { All Parents } & 22 & 10 & 12 \\ \text { Parents of Boys } & \ddots & 15 & 9 & 6 \\ \text { Parents of Girls } & & 7 & 1 & 6 \\ \begin{array}{l}\text { Parents Who Identified } \\ \text { Behavior Problems }\end{array} & 13 & 7 & 6 \\ \begin{array}{c}\text { Parents Who Identified } \\ \text { No Behavior Problems }\end{array} & 9 & 3 & 6 \\ \begin{array}{c}\text { Parents Who Acknowledge } \\ \text { School Intervention }\end{array} & 9 & 6 & 3 \\ \end{array}$

When they were asked where they did find help in dealing with behavior or adjustment problem, there were varied responses. Four parents went to mental health agencies and 4 to the University Medical School. Three went to teachers, 2 to the school psychologist, and 2 to private psychologists. Some of the parents noted a number of agencies to whom they had turned for help, but only 7 (53.8 percent) of the 13 parents noting behavior problems in their children mentioned the RPD as a source of help or referral.

Employment experience was considered an important 
factor in adolescent adjustment. When asked about the work experience of their teenage deaf child, most parents said their child had worked. Fifteen ( 68.2 percent) of the parents said their child had had a full time job at least during the summer and four (4) others said that baby-sitting, paper routes or field work were the extent of their child's experience. Of the 19 teenagers with some work experience, RPD was involved in securing the job in 9 cases, but 7 others found the jobs on their own.

Future Services.

The parent interview also sought information on where they plan to find necessary services in the future. Three areas of potential need were discussed: behavior problems, educational problems, and adjustment problems. Table IV presents the persons or agencies parents considered as potential resources in dealing with problems after high school, Parents see the RPD support staff as the most consistent resource to them with any kind of problem. Public and private mental health providers and the regular school personnel are the second most common resource suggested by parents. More than 33 percent of the parents said that they had no idea where to find services for adjustment problems, and did not see the RPD as a source of meaningful referral. 


\section{TABLE IV}

\section{RESOURCES FOR DEALING WITH FUTURE PROBLEMS, IDENTIFIED BY PARENTS}

\section{Resources}

Don't know

RPD Staff

Regular School (not RPD)

Teacher

Public/Private Agency

Portland Comm. College

Vocational Rehab.

Minister/Priest

Other Parents/Friends

Physician

Deaf Community

No Need $\frac{\text { Behavior }}{f^{\star} \delta^{* *}} \quad \frac{\text { Education }}{f} \frac{\text { Adjustment }}{f^{*} z^{* *}}$

4. $18.2 \quad 8 \quad 34.8$

$\begin{array}{llllll}7 & 21.2 & 4 & 18.2 & 4 & 17.4\end{array}$

$5 \quad 15.2$

$4 \quad 18.2$

$4 \quad 18.2$

$1 \quad 4.3$

515.2 .

$-$

$\begin{array}{ll}5 & 21.7\end{array}$

$4 \quad 18.2$

14.3

$-$

$4 \quad 12.1$

$4 \quad 12.1$

$4 \quad 12.1$

- -

$3 \quad 13.0$

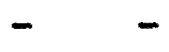

$-\quad-$

14.3

$-\quad-\quad 29.0 \quad-\quad-$

* Some parents noted more than one resource.

** Indicates the percentage of the responses in this category.

*** Less than 100 percent due to rounding.

When teachers and support staff at the RPD were asked where they would refer a parent or student with a problem, the most likely resource was the RPD psychologist. The ranked frequency of referrals suggested by staff are presented in Table $V$. 


\section{TABLE V}

REFERRALS SUGGESTED BY RPD STAFF FOR STUDENTS

WITH EMOTIONAL OR BEHAVIORAL PROBLEMS

\begin{tabular}{lc}
\multicolumn{1}{c}{ Referral } & Weighted frequency* \\
RPD Psychologist & 11 \\
RPD Social Worker & 8 \\
Teacher & 3 \\
Supervisor & 4 \\
Outside Agency & 4 \\
Parent Conference & 3 \\
\hline & \\
* RPD staff were asked to 1ist their \\
first second and third referral, \\
first choice was scored 3, second \\
choice 2, and third choice 1 point.
\end{tabular}

It should be noted that the responses recorded in Table $\mathrm{V}$ represent only two teachers and five support personnel. For this reason, mention is made of referral to teachers and parents as well as to other support staff. However, referral to an outside agency was not mentioned by the teachers or the support staff except the psychologist and social worker.

Service Delivery Problems.

In order to get some indication of the perceived breakdowns in the system of service delivery to deaf youth and their families, parents and RPD staff were asked to identify the most serious problems faced by deaf teenagers. Parents thought the biggest problems were social, noting 
social acceptance and social life in 9 cases. The lack of maturity or direction in the teenagers life and future problems with employment were rated as the second and third greatest concerns of parents. Teachers and staff tended to identify problems in their own field of expertise. Vocational counselors saw employment problems and teachers saw educational problems as most serious.

The final area of concern in the study was to ask parents and school staff to suggest improvements in the service delivery system. While one parent noted that less. involvement By school personnel would be an improvement, lil parents 140.7 percent of all responses) felt that increased information, cooperation and encouragement for parents by RPD staff would provide the greatest improvement in the system. When school staff were asked the same question, four areas of improvement were noted by two or more staff persons. Coordination among staff within the RPD and with outside agencies was seen as an Important improvement. Parent awareness and parent-teen communication training was suggested by two staff persons, and two mentioned the need for a residential unit for teens with temporary emotional and family problems.

\section{Discussion}

Incidence of Behavioral Problems.

The interviews with parents and survey of the teachers indicate that the incidence of behavioral problems in deaf teenagers is as least as high as among an entire school-age 
population. The sample is very small and has some variables that were not controlled, so exact estimates cannot be assumed. Only those parents and teachers who chose to return the questionnaires could be included in the study so there is a possibility that those who felt their child or. student was problemed would be more likely to respond. However the incidence of behavioral problems among teenagers in Portland may range from a high of 59.1 percent noted in parent ratings of their own children to a low of 27.3 percent when only those students rated as problemed by both parents and school are considered. For boys, the rate may be as high as 73 percent when ratings of parents alone are considered. It is important to note that both parents and teachers identified boys as"behavior problems more often than girls.

Service Availability.

Nearly half the parents of deaf teenagers received no real assistance in dealing with the emotional and informational needs associated with the diagnosis of deafness in their child. The lack of effective and accessible services is accentuated by the dependence of parents have on distant and incomplete sources of information like the John Tracy Clinic. Doctors and special clinics or centers provide only minimal help and knowledge to parents and it is often with. the pre-school teacher or other parents that the first affective support and sharing of resources is accomplished. The emotional trauma in most cases is struggled through 
without professional assistance or ignored in the hectic processes of diagnosis and prescription.

At school age, support and encouragement to parents is only slightly more visible. For children exhibiting behavior that is disruptive, the school becomes involved and parents usually find this intervention helpful. But for reasonably well adjusted, introverted or nondisruptive students the school provides very limited adjustment help contact or needs beyond the classroom are left unattended.

Future Services.

When faced with the transition from school to young adulthood, parents are, not surprisingly, frustrated and baffled by the service system. Almost half the sources of future help identified by parents were school personnel at the RPD or the regular high school. This probably indicates an awareness of the teacher is concern for their child, but the survey of RPD staff shows that teachers and most support personnel lother than those specifically trained in social service) are not aware of community resources and would not be a viable source of referral for future adjustment, education or behavior assistance.

While 40 percent of the parents note the primary need in service delivery is encouragement, information and cooperation; the school personnel see service delivery improvement in offering parent awareness classes and additional services for troubled teenagers. 
Personal Conclusion.

The results of this study though not conclusive, provide substantiation of previous research. Services are not easily accessible to parents or to deaf children. The fragmentation of services into medical, educational, and rehabilitative seems to offer minimal transition assistance and parents often have to seek out. services without referral.

Although hearing and speech centers and schools do intervene with parents, this usually occurs when the child has become a problem for the center or the school. When parents feel needs at home, the educational resources tend to provide no help if the problem is not expressed in the classroom.

Parents have expressed the need for a consistent, balanced and informative involvement by someone who is not committed to one profession or one life period. Parents could be assisted in their emotional and decision making crises by someone who is not limited by the child's age or his presenting condition. 
CHAPTER III

\section{MODELS OF SERVICE DELIVERY TO THE DEAF :}

\section{A SURVEY OF THE IITERATURE}

The preceding discussion has indicated that the deaf child and his family stand in need of special services across a broad range of professional interests. In addition to each individual service requirement, there is an apparent need for a direction to the service delivery and a comprehensive array of services. This chapter presents a brief investigation of the four principal models of delivery of social services to deaf people that are apparent in the literature. Each of the four models represents a specialty, but has attempted to increase the comprehension of service by incorporating other disciplines. These are the "demonstration" service systems, that represent the innovative approaches attempted or proposed by four specific service areas.

Vocational Rehabilitation Model.

Perhaps the oldest system through which a compliment of services are offered a client is the vocational rehabilitation movement. Wesson (1973) notes that the history of rehabilitation indicates that services were primarily the contribution of persons concerned about the welfare of crippled children and disabled war veterans. Hence the development of services 
in rehabilitation correspond to movements for services to children and legislation benefiting war veterans.

Rusalem and Baxt (1973) list 14 methodologies through which rehabilitation services are or could be delivered to citizens. These methods range from simple client initiative through utilizing the family or developmental system to involvement in community organization movements. According to their analysis of these methods for reaching clients, one factor remains, some clients will not be reached and some services will not be offered.

In a study of the organizational components of rehabilitation agencies, Wesson (1973), notes the multi-dimensional professionalism which must be involved to accomplish rehabilitation. It is not surprising that fragmentation, lack of coordination and inefficient referrals abound in so complicated a process. Physicians, therapists, social workers, psychologists, guidance counselors, educators, and prosthetists, to name only a few, are involved in the process from within two thousands different agencies nationwide.

In order to overcome some of the competition and confusion in delivering rehabilitation service, the federal. government has attempted integration and coordination through a comprehensive approach.

Thus the concept of the "rehabilitation center" has emerged as a suggested institutional norm for the field. This kind of institution, designed to meet the needs of the whole client was conceptualized as something new: They are not hospitals, schools, or industries, but partake of the characteristics of all these. (Wesson, 1973). 
The center model attempts to bring together all the professionals and para-professions involved in the process as a "team" rather than the hierarchical system found in a school or hospital.

In the field of deafness; this attempt to develop a center of services has been tried in several cities. Bolton (1975) has described one such center in Hot Springs, Arkansas. The components of a comprehensive center indicate the increased services necessary for vocational preparation of multi-handicapped deaf person. As described by Bolton (1975) the elements of the program are: (1) case management and counseling; (2) personal and social services such as supervised living and personal adjustment programs; and (3) vocational preparatory services, including skill training, evaluation, and work adjustment.

In the private sector, several cities have received federal demonstration money to establish comprehensive service centers. The Pittsburgh Counseling Center (Shrayer and Dillenburg, 1974) has become a model for other cities. Centers have also been established in Dallas, San Diego, Kansas City, Indianapolis, and several other cities (Spellman, 1974). The basic focus of such a community service center is to overcome the communication barriers that separate deaf persons from regular community services. Shrayer and Dillenburg (1974) comment, however, that some direct. service. is required of the community center since available service agencies in the community cannot or will not deal with some 
problems encounter by the deaf.

Perhaps the greatest drawback in these model centers is their scarcity. The Department of Vocational Rehabilitation considered this fact as a guiding principle in preparing a Model State Plan for Vocational Rehabilitation of the Deaf (1973). In areas where comprehensive centers are not available; the Model State Plan (1973: 7) affirms that "every deaf client has a right to be provided all the services he needs to achieve the degree of vocational independence that reflects his native abilities. These services must include. adjustment and vocational training, job placement, counseling and follow along services.

Personal Conclusion.

Although rehabilitation has been by far the most comprehensive deliverer of services, certain restrictions limit the continuity of service. The basis of rehabilitation service is vocational, and even though the severely disabled are to be considered, funding limits prohibit service delivery to the very young or the very old and focus primarily on work adjustment rather than personal problems. Once employment has been secured, the rehabilitation agency has accomplished its service delivery. Follow-up may be offer for a limited time, but subsequent personal, legal, emotional, or family problems are not within the service realm of vocational rehabilitation.

A wide variety of services are afforded clients under this model, but client accessibility is determined by 
employability and work status. Only adults and only those who require training and/or employment counseling are accepted for service.

Mental Health Model.

A second context within which some integration of services can be offered is a comprehensive mental health program. schlesinger and Meadow (1972d: 50) describe such a program from a community psychiatry base. The goals of such a program are prevention, reduction and relief of psychiatric illness with emphasis on the

provision of comprehensive services for the maximum number of patients and a systematic attempt to. mobilize and deploy community resources most efficiently and effectively for this purpose.

The mental health model differs from the rehabilitation model primarily in its concern for prevention rather than restoration. Mental health attempts to bring services to the primary and secondary level as well as the rehabilitative level, through community education and early intervention programs.

The literature identifies three comprehensive mental health programs for the deaf community in addition to the San Francisco program described by Schlesinger and Meadow (1972d). Altshuler and Rainer (1968) have described the comprehensive program of clinical services in New York which include consultation and collaboration with other agencies. St. Elizabeth's Hospital in Washington, D.C. has been the demonstration program of the federal government which not only trains personnel, but provides a wide array of clinical 
and evaluation services. In Illinois, disturbed deaf children and adults receive care from a joint project of the David Siegal Institute and Michael Reese Hospital which has been described by stein (1974). The most difficult cases in the Illinois program are identified as the 18-25 year old deaf patients who because of behavior and anti-social problems require a multitude of restorative services.

The conceptual model offered by Schlesinger and Meadow (1972d) emphasizes the essential character of a broad range of preventative services and specialties that must be involved in delivering comprehensive service.

Deafness is more than a medical diagnosis; it is a cultural phenomenon in which social, emotional, linguistic and intellectual patterns are inextricably bound together. It is not surprising that the deaf individual requires services from a multiplicity of disciplines. (53).

In order to adequately meet the needs of deaf persons within the context of the multiple services required for mental health, the conceptual model of community mental health requires not only clinical services but collaboration with other agencies, consultation and community organization. Personal Conclusion.

The great advantage of the mental health model is the inclusion of education and prevention services along with restorative treatment. Unlike the rehabilitation model, mental health is ideally concerned with the whole client. Service is coordinated in his work, family and personal adjustment and public awareness programs seek to prevent 
problems before they become serious.

The one drawback of this model is the limit of its scope. Even though prevention is a goal, restoration of clients with serious problems take the majority of time and effort. Also, it is only those deaf persons who have identified their problem as mental or emotional who will seek assistance. Those with legal problems, concerns about education or speech training still must fumble through the system without assistance or direction.

Professional Consultation Model.

In many circles, much attention has been paid to the necessity of educating those who deal with the deaf. If doctors were more sensitive to the psychological, educational and adjustment problems that their diagnosis initiates, a more fluid system of referrals could be provided the child and his family. Cooper (1971) has proposed a "non-system" that would involve the deaf community and parents of deaf children in a locally based campaign to provide information and assistance to professional in facilitating referrals. In the place of a monolithic government structure, Cooper suggests that critical stages in a deaf child's life be coordinated by the dominate agency involved at that stage. Doctors and hospitals, schools and rehabilitation facilities would become "centers of responsibility" for the coordination of services at the liffe stage when they are most involved with the child. Parents and deaf persons would serve as consultants about the 
multiple needs that must be met.

Another consultation approach has been attempted by the Social and Rehabilitation Service in establishing Regional Resource Centers for the Deaf. Walker (1974) describes the RRCD as providing information for the deaf and those who deal. with the deaf. The primary means of providing this information is through iiterature and consultative resources. The RRCD concentrates expertise on deafness that can be made available to a particular client or to an agency or organization. By training professions in short-term orientation programs, offering assistance to police departments and local jurisdictions, the RRCD can begin to provide some of the awareness that is so needed in the general public.

Another direction has been begun in Rhode Island where the school for the deaf has systematically widened its concern to include deaf adults (Spellman and Swain, 1974). Through an Adult Services Section, the school maintains contact with the adult deaf community and provides vocational counseling, continuing education and consultation. The outgrowth of this activity has been a greater awareness of the needs of deaf students and establishment of a vehicle for the continuing concern of school personnel for the welfare of deaf persons. School personnel have begun to serve as consultants to other agencies who deal with deaf clients. 
Personal Conclusion.

The services included under this model are not as clearly defined as in the previous models. The basic tenet that greater responsiveness can be drawn from the general system if occasional consultation makes service providers aware of the specific needs of the deaf. Perhaps the major obstacle to effectiveness in this model is the relatively small deaf population. Necessary providers like public welfare, courts and medicine have such infrequent contact with the deaf that professional workshops or awareness campaigns do not provide sufficient assistance to the professional or the client.

Information, Referral, Advocacy Model.

One final methodology for coordinating services to the deaf has been developed around the delivery of information. The Regional Resource Center (Walker, 1974) mentioned previously, is one incidence of this approach. Through computerizing lists of personnel, programs and facilities relevant to the needs of deaf persons and their families, the center staff can provide names and addresses of counselors, lawyers, or service centers by state, city or region. A directory of services for each state of the region is published annually to provide easy access to personnel and programs.

In recent years, many national organizations have become aware of the need to provide information about deafness. 
The Council of Organizations Serving the Deaf, Inc. brings together the major service organizations of the deaf in order to coordinate programming and provide nationwide information on services. The National Association of the Deaf has been a pioneer in bringing information to the adult deaf community as well as trying to influence the opinions of parents of deaf children and professionals in the field (Jacobs, 1974). Through their publishing house, their monthly magazine and chapters in every state, the N.A.D. brings information about teaching methods, athletic and vocational accomplishments and service improvements to deaf people throughout the country. Both organizations act as advocates for the deaf nationally with government, legislators and professional organizations.

In recent years, the federal government has organized a national office to provide information on services to handicapped children. The program called "Closer Look" is headquartered in Washington, D.C. Through consultation with parent groups and professionals as well as a newsletter and computerized information bank staff provide information on availability and assistance in development of services (Closer Look, 1976).

In order to make such information more useable to individual parents a system of local "direction services" have been funded through the Bureau of Education of the Handicapped (Monson, 1977). These local centers, now in the demonstration 
stage, serve various geographic locations from as small as a school district to as large as'a state. Servicés include not only information and referral, but limited case work with parents and follow-through services with agencies and programs.

\section{Personal Conclusion.}

Information is useful only when it can be related to a local situation. A national clearing house, no matter how comprehensive or efficient, cannot share the subtle distinctions that personal involvement makes possible. No one would deny the value and necessity of nationwide advocacy and information resources, but local knowledge is of utmost importance when services are needed.

The "Direction Services" offered by the federal government in local areas areafascinating possibility. They are too new to be evaluated in any real sense of the word, but since they are directed only at children, some mechanism needs to be developed for a smooth transition to adult service needs. The fact that at least one demonstration program is attached to a school setting has the potential of becoming involved in professional protection and inter-agency competition.

Summary .

A wide variety of services are offered or proposed to assist deaf persons and their families with information, direction, and comprehensive service. Each model approaches the client from a specific professional perspective. 
Rehabilitation, medicine, education, and information have all provided some coordination of service. However each source of service has limits of concern, usually based on age, serving either adults or children. Those models that cross age lines, such as mental health services, limit intake by requiring some pathology to qualify for service.

The information centers provide data across age and need categories, but have not been able to find the most adequate means for following through with clients and fully orchestrating the array of services that may be required at particular times and throughout the life of a deaf person and his family. 


\section{CHAPTER IV \\ SERVICE DELIVERY FOR THE DEAF:}

A SYSTEMS APPROACH

The research has cited the mounting concern over the expansive social service needs encountered by deaf persons and their families. Schlesinger and Meadow (1972) have found a significantly higher rate of behavioral problems among deaf children than among those children with normal hearing. They offer extensive data to indicate that services are needed throughout the development of the deaf child. The study reported here has indicated that parents of deaf children have no access to a comprehensive provider who can serve the developmental needs of their child, and they must wind through the maze of services each time a new problem is presented. Moores (1973) has shown that families of deaf children encounter particular stress periods when social services are of utmost importance and when these services are often least available because of the age and specialty fragmentation of the system. The report of the Rand corporation (Kakalik, et.al., 197.4: 15) shows the system itself overly complicated and without direction.

Insufficiency of resources is a major problem, but higher funding alone will not solve the basic problems that we find pervading nearly all aspects of the system: complexity, lack of control and disorganization. 
The system currently delivering services to handicapped youth defies efficient and effective. operation. .

The four basic models which have attempted to bring together the services needed by deaf persons and their families have not provided adequate coverage. The rehabilitation model is the most comprehensive, but focuses on employment as its goal. Because it is aimed at employability, the rehabilitation system is not available to young children, to families or to fully employed deaf adult.

The Community Mental Health model has been proposed and tested in several cities, provides education, prevention and treatment to deaf persons of any age. With limited funding however; those with the most serious problems receive the bulk of the attention, thus limiting the effectiveness of preventive services. Because it is organized as a mental health service, the program is pathology-specific in the minds of many deaf persons and their families and thus does not reach the other service needs encountered.

The other two models, consultation services and the information-referral-advocacy model; lack comprehension and specific involvment with clients. These programs become distant sources of assistance rather than direct service providers or immediate resources for specific guidance and direction.

The analysis of the literature calls for the formation of a new model which will encompass both the life span needs of the deaf person as well as the mulitude of needs encoun- 
tered by him and his family at specific stress points. The model must see the deaf person and his family in a holistic way, while continuing to impact the service environment in which the deaf person lives and grows. The model must find a means of providing accessibility, comprehensiveness and integration in service delivery. The model proposed here, is an attempt to accomplish these system needs for deaf people and their families.

Conceptual Framework.

In order to adequately develop a model. for intervention that wili meet the basic requirements of access, comprehensiveness and integration, a theoretical framework must be the foundation point. The fundamental concept of systems science underlies this attempt at model building. The writer has borrowed heavily from the work of William Gordon (1969) and Gordon Hearn (1970) in development of this framework.

To briefly summarize the basic constructs of the system approach, we can say that the universe is composed of a multitude of inter-locking systems. Each system is a living organism which is in constance contact with other systems that make up its environment. For purposes of clarity, the principal system (for example, the family) is seen as a living organism in contact with it's environment which is a complex of all those other systems which impinge upon it. The family's points of contact with the environmental systems are "interfaces" between the system and its environment. At the inter- 
faces" between the system and its environment. At the interface, "transactions" occur. This transaction is a blend of the system activity and the impinging environment and both are influenced by the transaction.

As graphically represented in Figure 1., the transactions occur at the system boundary and involve the open area of the system and the proximal area of the environment. It is important to note that the hidden area of the system and the distal environment are only indirect influences and are not directly involved in the transaction between the system and the environment.

The point of the transaction is a matching effort whose focus is the coping behavior of the system on the system side, and the qualities of the impinging environment outside the system. The transaction is an exchange, seeking enhancement at both sides of the interface. Both system and environment are changed by the exchange.

The fundamental goal of social work in this systems approach is to promote the growth and development of the organism, while at the same time being ameliorative to the environment. It is an attempt to reduce confusion and disorganization on both sides of the interface. As Gordon (1969: 11) states it:

The consequences of transaction for both organism and environment are therefore of concern-- in the one case, to reduce or extract entropy; in the other, to distribute the extracted entropy in a nondestructive way to the environment.

The role then, is to "recycle" the entropy (disorganization) 


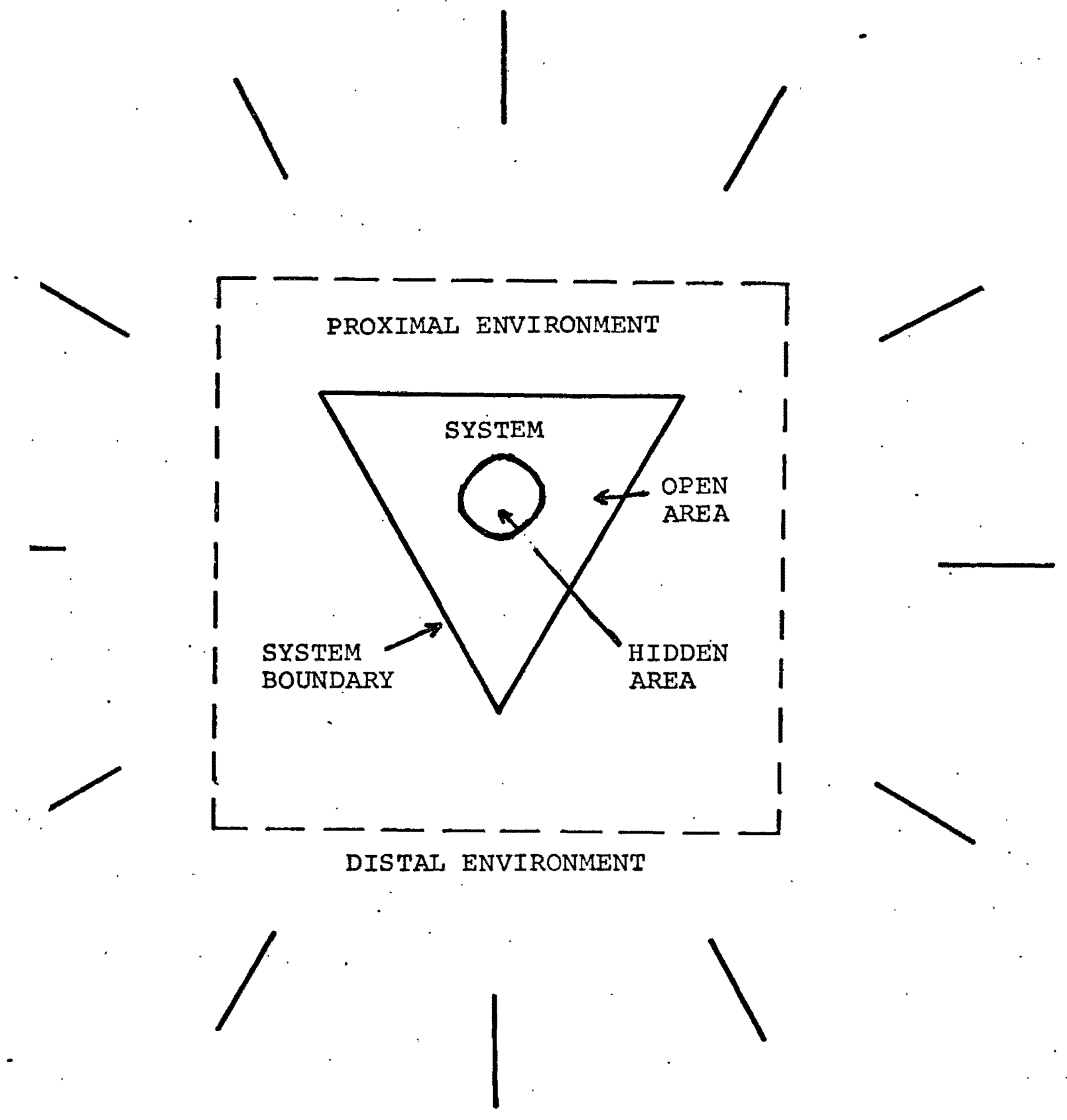

\section{FIGURE 1}

THE SYSTEMS UNIVERSE*

*Adapted from Hearn (1970). 
extracted from the system in a way that all the other systems in the environment will not be damaged.

Hearn (1970) develops a further analysis of the ecological role of social work by identifying three levels of system work. Whether dealing with an individual in a group, a group on an organization, or an organization in a community, social work is involved with systems at their interface with other systems in their environment. Figure 2. presents the three levels of social work intervention discussed by Hearn (1970). Level $I$ is system work at the interface between the hidden and apparent parts of the system itself. Level 2 is called boundary work and occurs in the regions where the system and the environment interface. At Level 3, environment work, the interface is between the distal and the proximal environments. There are actually six regions identified in Figure 2 since social work may be primarily involved at either side of each interface (i.e., for the system at the boundary: or for the environment at the boundary).

Developmient of a Model.

From this conceptual framework the social service needs of deaf persons and their families can best be met by specific boundary work. Many services exist to meet the special needs of the deaf, but the categorization of those needs leaves clients constantly seeking out new service providers for new presenting problems. It has been noted (Walsh, 1977) that initial support for emotional trauma of the diagnosis of 


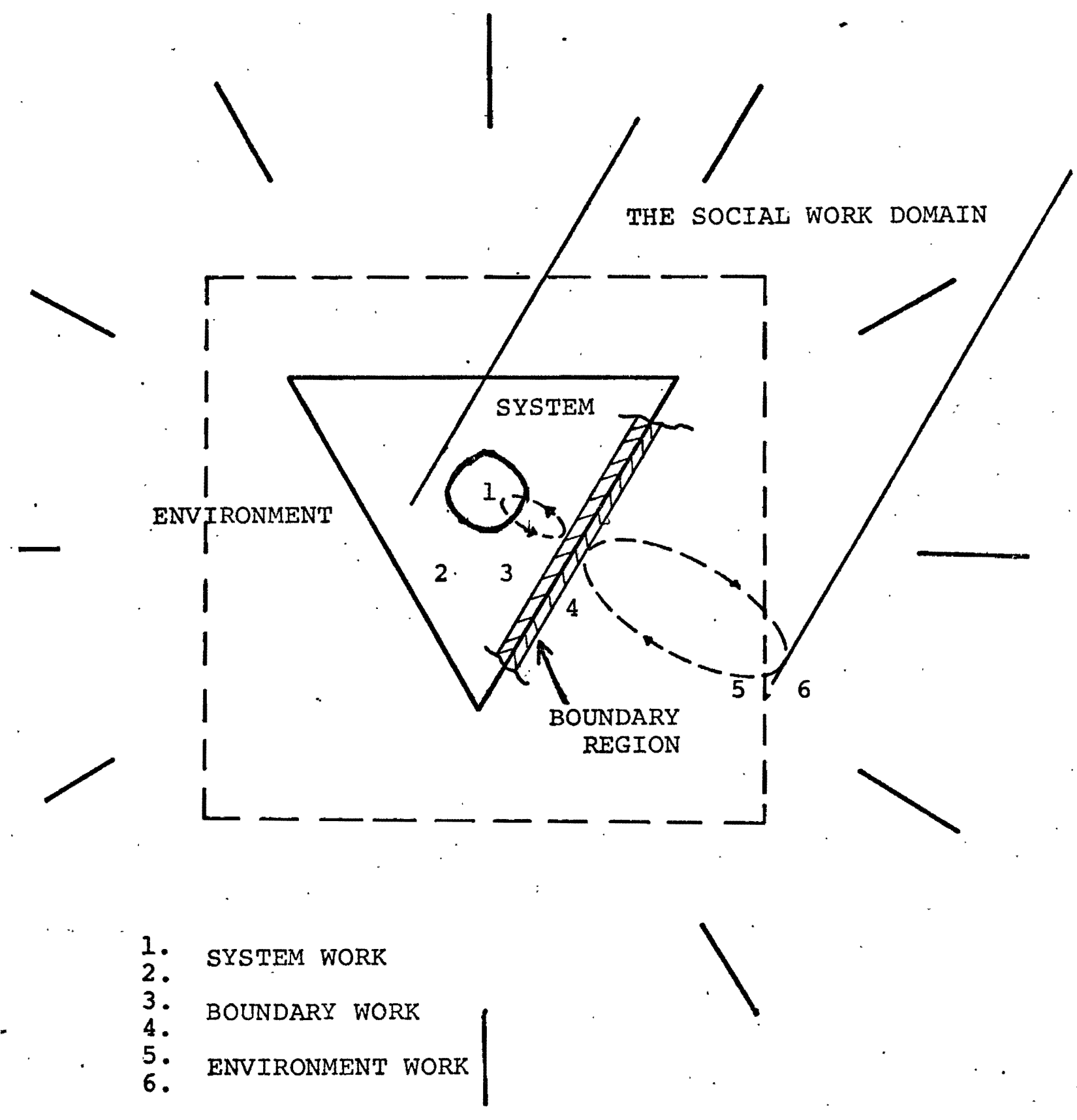

FIGURE 2

THE SOCIAI WORK DOMAIN*

*Adapted from Hearn (1970). 
deafness, complete and non-competative, educational and vocational information, preventive mental health services and adult life adjustment counseling are either not provided or not accessible to deaf persons and their families in most cases.

What is called for is a dual force in boundary work that can serve to connect individual families with necessary service providers, and can also impact the service systems so that integration and coordination of service delivery will be accomplished.

This model proposes a continuous boundary work service as one means of accomplishing this two-fold task. As shown graphically in Figure 3., this boundary work would be done at the specific stress periods identified by Moores (1973) and would be professional intervention for direction offering at the environmental transition points. The principal service environment from which the family system must draw support (the impinging environment) changes at least five times during the life cycle of the child. Moving from the medical environment in which the original diagnosis occurs through. education, adjustment, vocational and adult service environments. As shown in Figure 3., intervention is required at all the shaded boundaries-- between the system and the environment at each stage, and between the successive primary environments.

In his discussion of social work as boundary work, Gordon Hearn (1970) identifies these seven functions as loci 


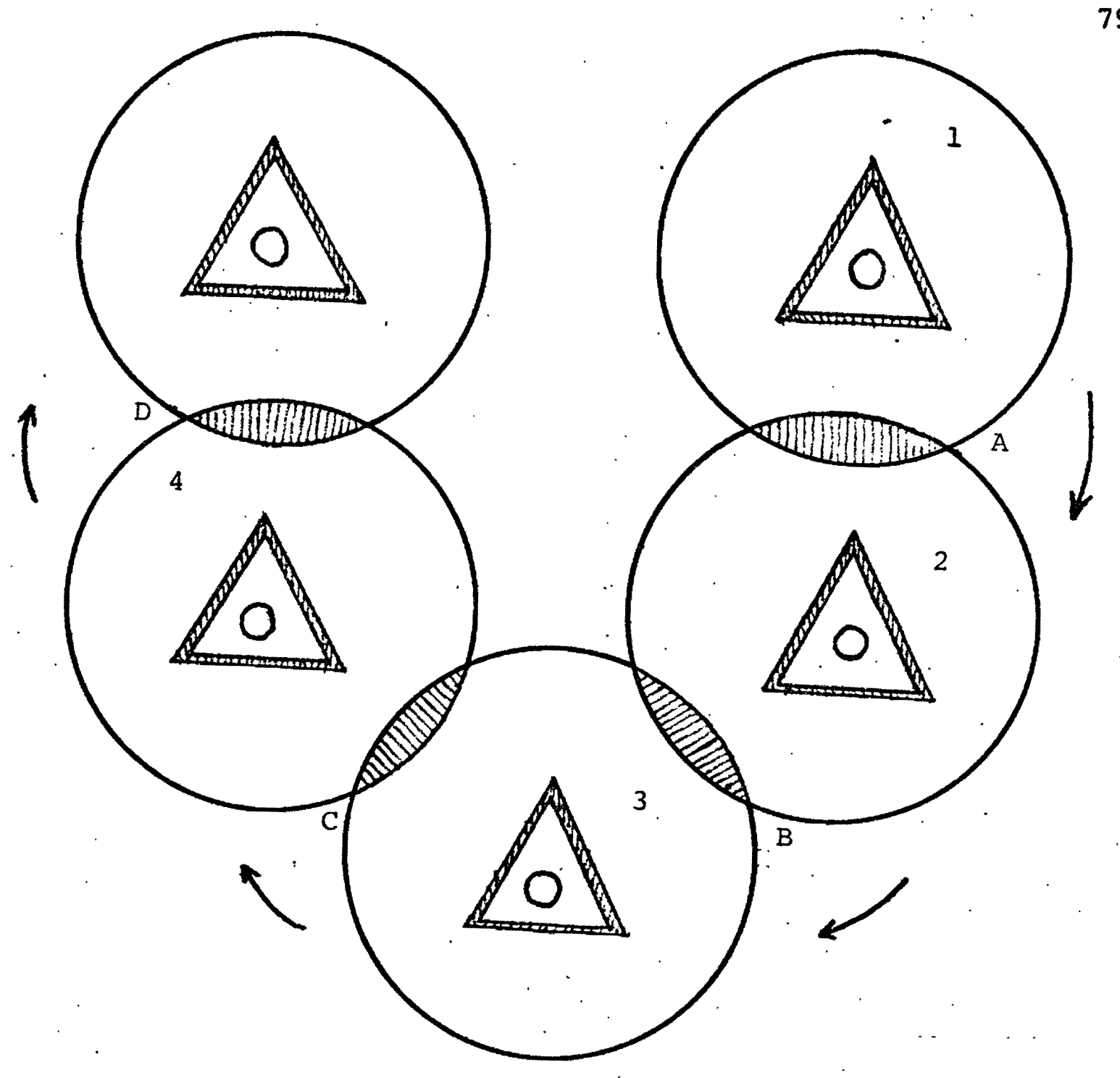

. Environment Transitions

A - Medicine-Education

B - Education-Adjustment

C - Adjustment-Vocation

D - Vocation-Adult Services
Family Stress Periods

1 - Identification

2 - School Entrance

3 - Begin. Adolescence

4 - Young Adulthood

5 - Adulthood

FIGURE 3 
of boundary work in the systems approach: (1) locating the boundaries; (2) regulating the degree of openness; (3) controlling the input and output of the system; (4) facilitating the filtering mechanisms of the system; (5) regulating the form of exchanges; (6) assisting in defining the stringency of the boundary; and (7) determining how much should be included in the system boundary. As conceived of here, boundary work is not rehabilitation or mental health intervention, its unique contribution to the system and the service providing environment is "direction."

"Directive Intervention" seeks first of all to match the family (the system) with those factors in the environment which will assist the system's coping mechanisms at each stage of development. However, since boundary work is also concerned with the amelioration of the environment, this directive intervention must also strengthen the environmental system by working at the environment-environment boundaries. The following portion of this paper will focus on each of these two intervention needs and then propose a specific model for providing this directive intervention.

\section{Access Service.}

To serve the complex needs of deaf persons and their families in a continuous and integrative way, the general literature on service coordination can offer insights. Particularly germane to the needs identified here are the access services which have been described by Alfred Kahn (1970). He 
sees specific access service as a function within a delivery network for three reasons.

First, the provision of access is of itself a significant social service. . . Second, an access service system with adequate feedback and reporting machinery can contribute to identifying qualitative and quantitative lacks in the service system and can contribute significantly to the planning process. Finally, even given the continuing service gaps, decent access services can end the conspiracy of silence or organized obfuscation that perpetuate inequality of usage. (p. 95)

The development of services aimed specifically at access began with the public health outreach activities of the 1950's and took on fuller meaning during the community action programs of the 1960's. The hope was to make the delivery system more accessible by sensitizing the public in the first instance and the service providers in the second.

No matter how accessible an individual service may be, there remains the need for an all-encompassing access service. Kahn (1970) points out that the protection of continuous and comprehensive care demands that the information-advice-referal source be autonomous from direct service delivery sources. The need for situation follow through and persistence does not lend itself to specialized delivery programs, and professional and organizational biases can hinder the provision of truly comprehensive and proper service information and referral. There is no argument with professionals' commitment to the best interests of the client, but

- . professional and organizational perspectives do affect the ways in which a problem is perceived and structured, the values that are held supreme, 
the priorities given to components of and sequences in a solution to a family's difficulties, and the "costs" to be tolerated for given outcomes or "benefits." (p. 99)

As described here, the Directive Intervention service. would attempt to mediate for the sake of the family between its own coping mechanisms and the professional values, perspectives and organizational biases of service providers. Kahn suggests the necessity of this service being provided outside the direct service agency (separate from the principal environment), so that continuity as well as critical decisions can'be measured and evaluated by the family.

coordinating Service.

This system-environment boundary work is only one part of the direction intervention necessary to view the familyin-need in a holistic way. The successive environments from which services are drawn overlap at critical points of stress in the family life of a deaf person. This has been graphically presented in Figure 3. In most cases these varied services are not coordinated or integrated to relate to the advancement of the whole family or to every aspect of the deaf person's iife. An intervention at the environment overlap is also necessary. The environment must be recognized as a system of providers each requiring boundary work between itself and other specialty systems. Only if the specialty systems can be mediated and integrated can the entire system provide holistic services. 
Van de Ven (et. al., 1975) distinguishes three ways in which the environment can be conceptualized: (i) as an external constraining phenomenon, (2) as a collection of interacting organizations, and (3) as a social system. Since our concern is with the environments impact on families rather than what the environment does independently, the second conceptualization is more relevant to our model. We are concerned with how groups of organizations within the environment establish exchange relationships in order to accomplish their goals. "Organizational exchange is any voluntary activity between two or more organizations which has consequences, actual or anticipated, for the realization of their respective goals or objectives" (Levine and White, 1961: 588).

Perhaps an example from the field of deafness will

serve to clarify this point. The vocational rehabilitation agency that serves deaf clients has as a goal the best feasible employment placement of the deaf client. In order to accomplish this goal, it has to engage in an exchange with a community college to provide employment training. The college can, in turn, attain its goal of developing innovative programs in vocational education because of the assured interest of the rehabilitation agency. Hence both agencies can attain their goals only through an organizational exchange. The focus of the model of "direction intervention" is to facilitate these exchanges so that the deaf person or his family is served in an integrated, holistic way. The concern here is to determine in what way coordination among the 
organizations in the environment can be maximized.

Jerald Hage (1975) argues that a great many "linkages" between organizations have been identified, particularly in sharing information and clients. However, he notes, these organizational networks are often sequential since many clients require services at different stages. Hage suggests joint programming as the definition of interdependence between organizations. This assumes that."the production process requires joint efforts or teams that transcend organizational boundaries" (p. 213). What is required is not a chain of cooperation, but a configuration of interdependence.

Other researchers have noted (Van de Ven, et. al., 1975) that the process of getting organizations to work together is complicated by the intra-organizational needs of each organization. The need for autonomy and domain consensus, as well as competition for scarce resources puts similar agencies in conflict rather than eager for cooperation and interdependence. Litwak and Hylton (1962: 399) point out this as the great difficulty in service integration.

One strategic problem in interorganizational analysis concerns co-ordination, a somewhat specialized coordination, since there is both conflict and cooperation, and formal authority structures are lacking. . $\quad$ The organizations being coordinated are independent, because they have conflicting values or because the demands of efficiency suggest organizational specialization, yet they share some common goals which demand cooperation.

Some mechanism or relationship must be developed which will provide the interdependence necessary for goal attainment (i.e., comprehensive services for deaf persons and their 
families) while still respecting the basic autonomy of each organization.

In their studies of orientation towards clients as a factor in interorganizational collaboration, Lefton and Rosengren (1966) distinguish organizations in a lateral and longitudinal concern analysis. An organization can offer many services (plus lateral) or be very specific in its service (minus lateral). Similarly, it can maintain concern for its clients for a long time (plus longitudinal) or have a very short treatment period (minus longitudinal). In a subsequent study (Rosengren, 1968) it was found that (among hospitals, at least) newer organizations had broad but short term concern for their clients, while older organizations tended to become specifically focused but involved for a long time with their clients. With this background, Rosengren (1970: 134), suggests this development of an organization:

Many service organizations begin life with a broadly focused but short-term interest in clients. This occurs because if the need to collect clients, garner community support and to survive initially without access to the predominant organizational set.

As they age, they tend toward specific and longterm orientation toward clients. This happens because of the press of norms of rationality, perfection of technology, membership in the organizational set, and the need to retain a hold on clienteles in order to sustain relationships with other organizations in the environment.

Considering this development of competing organizations in the environment, a single organization cannot provide the continuity and comprehension required, nor is self-initiated 
collaboration going to include the services necessary to serve the whole client. What is indicated is the need for an interdependence mediator who is outside the conflicts over autonomy, resources and domain. Some outside organization must intervene at the interface between separate delivery systems in order to initiate joint programming and comprehensive delivery for the client.

A Direction Intervention Service Organization.

This analysis of the service needs of deaf persons and their families has indicated the need for specific intervention at both the family-environment boundary and at the Boundaries between special service providers within the environment. The research suggests that the provision of access assistance can provide information on, critical appraisal of, and proper referral to the various service providers. This is direction intervention at the system level. Within the environment intervention is seen as non-competitive mediation for collaboration to accomplish specific interdependent goals among agencies serving deaf persons and their families. In order to accomplish this dual focus of direction intervention service, three factors are required.

First, the direction-intervention services must be provided by an agency who is not competing for limited resources. Therefore this service cannot be an adjunct of direct service provision, nor can it be identified with one professional specialty or value system. The agency should be a private, 
non-profit organization which is directed by consumers and managed by persons respected by the various professional specialties. The private status removes the threat to organizational autonomy while the consumer directions offers a degree of authority.

The second essential factor is knowledge of the various professional stances involved in the service environment. The staff of this non-profit agency must be aware of the services offered and the organizational biases of each service provider. This knowledge and the broad view it affords will be the basis from which intelligent referral and interorganizational collaboration can be directed.

Finally, the direction-intervention service must seek out families at the time when deafness is diagnosed and provide immediate, accurate and complete information. Part of this service is to assist families to realize the impact of deafness on their child's life and their own and to guide them with information and referral into and through the service providing system. If contact is made early and intervention is informative, honest and directive, the agency will maintain itself as a continuing resource to the family and later to the deaf adult himself. Through this continuity of concern and involvement, the interorganizational expertise of the agency is enhanced and collaboration will become a meaningful option for individual families and the service system as a whole. 
SELECTED BIBLIOGRAPHY

Altshuler, K.z. 1974. "The Social and Psychological Development of the Deaf Child: Problems, Their Treatment and Prevention." American Annals of the Deaf 119: 365-376.

Altshuler, K.z. and J. Rainer. 1968. Mental Health and the Deaf: Approaches and Prospects. Washington, D.C.: Department of Health, Education and Welfare.

Babbige, H.D. 1965. Education of the Deaf. A Report to the Secretary of Health Education and Welfare by The Advisory Committee on Education of the Deaf. Washington, D.C.: Department of Health, Education and Welfare.

Barker, R.G., B.A. Wright, L. Meyerson and M.R. Gonich. 1953. Adjustment to Physical Handicap and Illness: A Survey of Physique and Disability. (Revised Edition). New York: Social Science Research Council.

Barsch, R.H. 1968. The Parent of the Handicapped Child: A Study of Child Rearing Practices. Springfield, IL: Charles Thomas, Inc.

Beaird, J.H., J.J. McDonnell and L.M. Carl. 1972. Education of Oregon's Sensory Impaired Youth. Monmouth, OR: Teaching Research, Oregon College of Education.

Berlinsky, S. 1952. "Measurement of Intelligence and Personality of the Deaf: A Review of the Literature." Journal of Speech and Hearing Disorders 17: 39-54.

Best, P.K. 1973. "A Review of Deafness and Mental Health: A Developmental Approach." Journal of Rehabilitation of the Deaf 7: 15-22.

Boles, G. 1959. "Personality Factors in Mothers of Cerebral Palsied Children." Genetic Psychology Monograph 59: 159-218.

Bolton, B. 1975. "Preparing Deaf Youth for Employment." Journal of Rehabilitation of the Deaf 9, 1: 11-16.

- (Ed.). 1976. Psychology of Deafness for Rehabilitation Counselors. Baltimore, MD: University Park Press. 
Bowe, F., D. Watson and G. Anders. 1973. "Delivery of Community Services to Deaf Persons." Journal-of Rehabilitation of the Deaf 7,1: 15-29.

Brill, R.G. 1960. "A Study in the Adjustment of Three Groups of Deaf Children." Exceptional Children 6: 42-48.

Chough, S.K. 1973. "Social Services for Deaf Citizens: Some Proposals For Effectiveness." Deafness Annual, Volume III. Silver spring, MD: Professional Rehabilitation. Workers with the Adult Deaf.

Clark, G.M. 1975. "Mainstreaming for the Secondary Educable Mentally Retarded: . Is It Defensible?" Focus on Exceptional Children 7: 2 .

Cooper, L.Z. 1971. "Deafness: One Physician's View." In D.E. Hicks (ed). Medical Aspects of Deafness: National Forum IV. Washington, D.C: : Council of Organizations Serving the Deaf. 5-14.

Craig, W.N., J.M. Salem and H.B. Craig. 1976. "Mainstreaning and Partial Integration of Deaf with Hearing Students." American Annals of the Deaf 121, 2: 63-68.

Crittenden, J.B. 1975. "Psychology of Deafness, Some Implications For Interpreters." Journal of Rehabilitation of the Deaf $8,4: 19-22$.

DiCarlo, L.M. and J.E. Dolphin. 1952. "Social Adjustment and Personality Development of Deaf Children: A Review of the Literature:" Exceptional Children 8: 111-118.

Elser, R. 1959. "The Social Position of Hearing Handicapped Children in Regular Grades." Exceptional Children 25: 305-309.

Evans, D.A. 1975. "Experiential Deprivation: Unresolved Factor in the Impoverished Socialization of Deaf School Children in Residence." American Annals of the Deaf $120,6: 545-552$.

Farber, B. 1959. "Effects of a Severely Mentally Retarded Child on Family Integration." Monographs in Social Research on Child Development 24 .

Fellendorf, G.W. and I. Harrow. 1970. "Parent Counseling 1961-1968." Volta Review 1970, I: 51-57.

Force, D. 1956. "Social Status of Physically Handicapped Children." Exceptional Children 23: 104-107, 132-134. 
Freeman, R.D., S.F. Malkin and J.D. Hastings. 1975. "Psychosocial Problems of Deaf Children and Their Families: A Comparative Study." American Annals of the Deaf 120, 4: $391-405$.

Furth, H.G. 1973. Deafness and Learning: A Psychological Approach. Belmont, CA: Wadsworth Publishing Co., Inc.

- 1966: Thinking Without Language: Psychological Implications of Language. New York: The Free Press.

Garretson, M.D. 1969. "Social Adjustment of Deaf School Leavers in the U.S." Journal of Rehabilitation of the Deaf 2, 4: 42-50.

Goffman, E. 1963. Stigma, Notes on the Management of Spoiled Identity. Englewood Cliffs, NJ: Prentice Hall, Inc.

Gordon, W.E. 1969: "Basic Constructs for an Integrative and Generative Conception of Social Work." In: The General Systems Approach: Contributions Toward an Holistic Conception of Social Work. G. Hearn (Ed.). New York: Council on Social Work Education.

Grinker, R.R. et. al. 1969. Psychiatric Diagnosis, Therapy and Research on the Psychotic Deaf. Washington, D.C.: Social and Rehabilitative Services.

Grosser, C.F. 1973. New Directions in Community Organizing: From Enabling to Advocacy. New York: Praeger Publishers.

Hage, J. 1975. "A Strategy for Creating Interdependent Delivery Systems to Meet Complex Needs." In: Interorganization Theory. A.R. Negandhi (Ed.). Kent, OH: Center for Business and Economic Research, Kent State University. 210-234.

Hardy, R.E. and J.C. Cull. 1974. Educational and Psychological Aspects of Deafness. Springfield, IL: Charles .c. Thomas, Publishers.

Hearn, G. 1970. "Social Work as Boundary Work." Mimeographed presentation at Third Annual Institute on Services to Families and Children, University of Iowa, April 9, 10, 1970.

Jacobs, L. 1974. "The Community of the Adult Deaf." American Annals of the Deaf 119, 1: 40-49. 
Joint Commission on Mental Health of Children. 1970. Crisis in Child Mental Health: Challenge for the 1970's. New York: Harper and Row.

Kahn, A.J. 1970. "Perspectives on Access to Social Services." Social Work 15, 2: 95-101.

- 1972. "Public Social Services: The Next Phase-Policy and Delivery Strategies." Public Welfare 30, 1: 15-24.

1973. Social Policy and Social Services. New York: Random House.

Kakalik, J.S., et. al. 1974. Improving Services to Handicapped Children: With Emphasis on Hearing and Vision Impairments. Santa Monica, CA: Rand Corporation $(\mathrm{R}-1420-\mathrm{HEW})$.

Kennedy, A.E.C. 197.3. "The Effects of Deafness on Personality." Journal of Rehabilitation of the Deaf 6,3 .

Kennedy, P. and R.H. Bruininks. 1974. "Social Status of Hearing Impaired Children In Regular Classrooms." Exceptional Children 40, 5: 336-342.

Lefton, M. and W.R. Rosengren. 1966. "Organizations and Clients: Lateral and Longitudinal Dimensions." American Sociological Review 31: 802-810.

Levine, E.S. 1962. "Psychological Considerations In Early Profound Deafness." American Annals of the Deaf 107, 5: 530-543.

Levine, S. and P.E. White. 1961. "Exchange as a Conceptual Framework for the Study of Interorganizational Relationships." Administrative Science Quarterly 5: 583601 .

Liwak, E. and L. Hylton. 1966. "Interorganizational Analysis: A Hypothesis on Co-ordinating Agencies." Administrative Science Quarterly 11: $31-58$.

Marshal1, W.J.A., D.E. Hicks and R. Dantona. 1974. "The Diagnosis and Treatment of the Hearing Impaired Child: An Appraisal of Services." Deafness Annual, Volume IV. Silver Spring, MD: Professional Rehabilitation Workers with the Adult Deaf. 55-71.

McClure, W.J. 1966. "Current Problems and Trends in the Education of the Deaf." Deaf American 18: 8-14. 
- 1972. "Mental Health and the Hearing Impaired." Deaf American 23: 7-12.

Meadow, K.P. 1968a. "Early Manual Communication in Relation to the Deaf Child's Intellectual, Social and Communicative Functioning. American Annals of the Deaf 113: 29-41.

- 1968b. "Parental Responses to the Medical Ambiguities of Deafness." Journal of Health and Social $\therefore \quad$ Behavior 9: 299-309..

19.76. "Personality and Social Development of Deaf Persons." In: Bolton, B. (Ed.). Psychology of - Deafness for Rehabilitation Counselors. Baltimore, MD: University Park Press. 67-80.

\section{$\therefore \quad$ 1969. "Self-Image, Family Climate and Deaf- ness." Social Forces 47: . 428-438.}

Meadow, K.P. and H.S. Schlesinger. 1971. The Prevalence of Behavioral Problems in a Population of Deaf School Children." American Annals of the Deaf 116, 3: 346348 .

Mindel, E. and M. Vernon. 1971. They Grow in Silence: The Deaf Child and His Family. Silver Spring, MD: National Association of the Deaf.

Moores, D.F. 1973. "Families and Deafness." Deafness Annual, Volume III: 115-130. Silver Spring, MD: Professional Rehabilitation Workers with the Adult Deaf.

Myklebust, H. 1960. The Psychology of Deafness, Sensory Deprivation, Learning and Adjustment. New York: Grune and stratton.

Office of Demographic Studies. 1972. "Characteristics of Hearing Impaired Children Under Six Years of Age, United States: 1970-71." Washington, D.C.: Gallaudet College.

1973. "Characteristics of Hearing Impaired Students by Hearing Status, United States: 1970-71." Washington, D.C.: Gallaudet College.

Quigley, S.P. and R.D. Frisina. 1961. "Institutionalization and Psycho-educational Development of Deaf Children." Council for Exceptional Children Research Monographs, Series A., Number 3 . 
Rainer, J.D. 1970. Expanded Mental Health Care for the Deaf: Rehabilitation and Prevention. New York: New York State Psychiatric Institute, Columbia university Press.

Rainer, J.D., K.Z. Altshuler and F.J. Kallman (Eds.). 1963. Family and Mental Health Problems in a Deaf Population. Columbia University Press.

Rivlin, A.M.' 1971. Systematic Thinking for Social Action. Washington, D.C.: The Brookings Institution.

Ross, A.O. 1964. The Exceptional Child in the Family: Helping Parents of Exceptional Children. New York: Grune and Stratton.

Rosengren, W.R. 1968. "Organizational Age, Structure and Orientation Toward Clients." Social Forces 47: 1-11.

- 1970. "The Careers of Clients and Organizations." In: Organizations and Clients. W.R. Rosengren and M. Lefton (Eds.). Columbus, OH: Charles C. Merrill Publishing Co.

Schein, J.D. 1968. "The Deaf Community" studies in the Social Psychology of Deafness. Washington, D.C.: Gallaudet College Press.

Schein, J.D. and M.T. Delk. 1974. The Deaf Population of the United States. Silver Spring, MD: National Association of the Deaf.

Schlesinger, H.S. 1969. "Beyond the Range of Sound: The Non-onto-logical Aspects of Deafness." California Medicine 110: 213-217.

- 1972. "Diagnostic Crisis and Its Participants." Deafness Annual, Volume III. Silver Spring, MD: Professional Rehabilitation Workers with the Adult Deaf.

Schlesinger, H.S. and K.P. Meadow. 1972a. "Development of Maturity in Deaf Children." Exceptional Children 39: 461-467.

- 1972b. "Emotional Support to Parents: How, When, and By Whom." Parent Programs in Child Development Centers: First Chance for Chilaren. Mimeo reprint.

1972c. Sound and Sign: Childhood Deafness and Mental Health. Berkley, CA: University of California press. 
1972d. "A Conceptual Model for a Program of Community Psychiatry for a Deaf Population." Community Mental Health Journal, Volume $8,1: 47-5 \overline{9}$.

Schroedel, J.G. and W. Schiff. 1972. "Attitudes Towards Deafness Among Several Hearing Populations." Rehabilitation Psychology 19, 2: 59-70.

Schuldt, W.J. and D.A. Schuldt. 1972. "A Review of Recent Personality Research on Deaf Children." In: Trapp; E.P. and P. Himelstein (Eds.). Readings in the Exceptional Child. (Revised Edition). New York: Appleton-Century Crofts, Inc.

Shears, L. and C. Jensema. 1969. "Social Acceptability of Anomalous Persons." Exceptional Children 36: 91-96.

Stuckless E.R. and J.W. Birch. 1966. "The Influence of Early Manual Communication. on Iinguistic Development of Deaf Children." American Annals of the Deaf 111, 3: 452-462.

Van de Ven, A.H., et. al. 1975. "Frameworks for Interorganizational Analysis." In: Interorganization Theory. A.R. Negandhi (Ed.). Kent, OH: Center for Business and Economic Research, Kent State University.

Vernon, M. 1968. "Fifty Years of Research on the Intelligence of Deaf and Hard of Hearing Children: A Review of Literature and Discussion of Implications." Journal of Rehabilitation of the Deaf $1,4: 1-12$.

Vernon, M. and S. Koh. 1971. "Effects of Oral Preschool Compared to Early Manual Communication on Education and Communication in Deaf Children. American Annals of the Deaf 116: 569-574.

Youngs, J.P. 1975. "Experiential Deprivation: A Response." American Annals of the Deaf $120,6: 552-554$.

Zuk, G.H. 1962. "The Cultural Dilemma and Spiritual Crisis of the Family with a Handicapped Child." Exceptional Children 28: 405-408.

- 1959. "The Religious Factor and the Role of Guilt In Parental Acceptance of the Retarded Child." American Journal of Mental Deficiency 64: 139-147. 


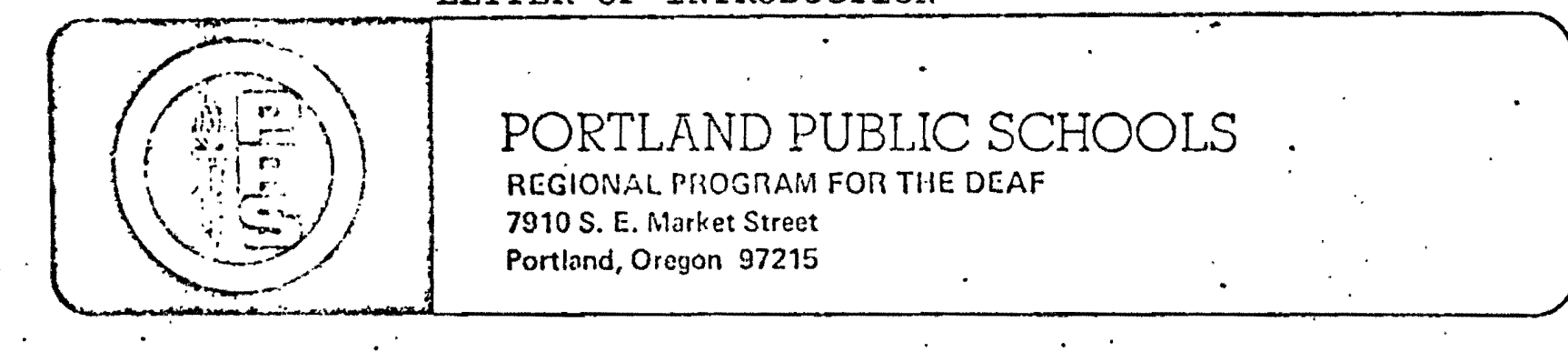

November 24, 2976

Dear Parents,

We are always anxious to enhance the total well-being of your hearing-impaired children and our students. We are proud to be offering one of the finest educational programs in the Northwest. A part of maintaining high standards, however, is being constantly critical of oursel.ves and our sexvices, Inrough evaluation we can find new ways to aid your chiloren in preparing for a fuller Iife.

Recently Mr. Patrick Walsh, a graduate student at Portiland State University, has offered to assist us in identifying and evaluating the "special services" we offer our students and their parents. Mr. Waish has had considerable experience with hearing-impaired persons throughout orcgon and we velcone this opportunity to take a critical look at this secondary but very important part of our total program at the Regional Facility.

$\because$ The research will require "tracking" the servjces provided students who experience special problems because of behavioral, cmotional or personal difficulties. To make this study comprehensive, we need both your input and your permission to look at the services offered your child.

The usefulness of Mr. Walsh's study depends on the full cooperation of all of us, faculty, staff and parents. Please take a.few moments to answer the brief questionnaire enclosed. There is also a form entitled "Consent to Release of Information" enclosed which the law requires if we are to identify the services provided to your child.

of course, the information gathered by this study will be maintained in strictest confidence. All the material will be used only by Mr. Walsh and only for this study. It will not be shared with any other agency and your child will not be discussed except in connection with specific. services offered by the Regional Facility.

Thank you for your cooperation with $\mathrm{kr}$. WaIsh and your continued support and assistance in providing hich quality services for the hearing-impaired in the Portland area. If there are any questions, feel free to call me.

sincerely jours,

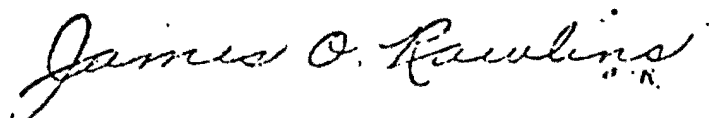

James. 0. llawlins

Supervisor 
EVEN IF YOU CHOCJE NOT TO GIVE PERMISSION FOR A "TRACKING" OF YOUR HEARIM-IMPAIRED CHILD, FLEASE' SILAEE THIS IMFORMATION WITH US.

1. What is your ch1ld's age? ( ) malo ( ) female

2. How long has your child been Involved with the Reglonal Facllity? years.

3. How rould you characterize your child's hearling loss?

$$
\left\{\begin{array}{l}
\text { nlld } \\
\text { moderate } \\
\text { sovere } \\
\text { profound }
\end{array}\right.
$$

What $1 \mathrm{~s} \mathrm{his/her} \mathrm{db} \mathrm{20ss?}$ db 1035

4. Kow well can your child understand spaech?

$$
\left\{\begin{array}{l}
\text { understands most rords and sentences } \\
\text { understands some kords and phrases } \\
\text { understands a few sounds and occassional rords }
\end{array}\right.
$$

5. How well does your child talk?

$$
\left\{\begin{array}{l}
\text { relatively easy to understand } \\
\text { can say a few phrases } \\
\text { can say a few words } \\
\text { can make only non-verbal sounds }
\end{array}\right.
$$

$\because$ 6. Can your child lip read? ( ) yes ( ) vo

$$
\text { IF YES, How nell? }
$$

7. Does your child use "total communication" or sign language?

$$
\text { () yes () no }
$$

8. Do you or any members of your family use total comanlcation or the 81gn langauge of the deaf?

$$
\text { () YES ( ) No }
$$

9. Does your child seom to get along well whth other children his/her orn age?

10. Have you ever sought inforsation or professional assistance to cope With your child's behavior or an exotional problem?

() $\mathrm{YES}$ () No

If YES, ploase explain the problem or problems that caused concerns 
11. Has the Reglonal Faclilty for the Deaf or any school-relsted.person over contacted you regarding your child's bohavior or an emotional problem?

() YES ( ) No

IF YES, briefly ldent1fy the kind of problem or problems that caused the school to callt

12. With whom does your chlld spend most of his/her time outside of school?

$$
\left\{\begin{array}{l}
\text { Mostly with hearins-inpalred children } \\
\text { Mostly with normal-hearing chlldren } \\
\text { About evenly mixed Hith hearing and deaf children } \\
\text { Mostly within the fanily, has fek outside friends } \\
\text { Mostly alone, watching T.V., reading, etc. } \\
\text { I don't know exactly who his/her friends are. }
\end{array}\right.
$$

13. Do you feel that your child could benefit from speclal services beciuse of an emotional or behavioral problem?

YES, he/she needs help Not at the present time, but in the past help was needed I feel we parents could have benefited from special help Ho, I don't see any need

14. Are there any cominents ox explanations you would 11ke to include?

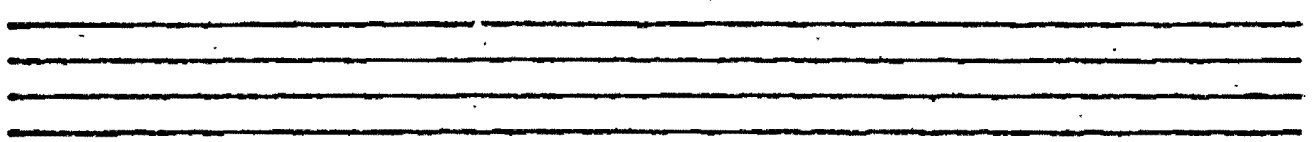

EVEN IF YOU IO NOT UISH TU PARTICTPATE FURTHER:

Please return this questionnalre in the envelope provided. THANK YOU. - B

15. Are you willing to assist us in evaluating the present special services that are offered problemed children by agreeing to a follow-up interview In your home and granting your consent to release information to us regarding the services that have been provided to your child?
( ) YES
( ) no

If YES, please give us this infornation and fill-out and sign the "Consent to Release of Information" form which is attached.

(your nase)

(address)

\section{(ch11d's name)}

(Phone nurber)

The best time to contact me by phone is: 


\section{APPENDIX C}

CONSEMT TO RELEASE OF INGORMATION

I hereby authorize Mr. Patrick Nalsh, In conjunction with the Portland Regional Facility for the Deaf to

(1) Reviex any records or reports, regardless of their source, relating to the educational, emotional or health treatment of since his/her enroll(child's name)

ment in the Portland Reglonal Facility for the Deaf on

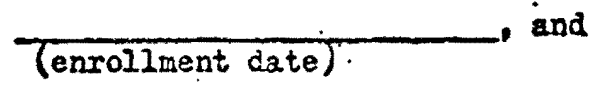

(2) Interviow any individual involved in the training, care or treatment of (child's name) since his/her enrollaent in the program.

I understand that any inforration gained from these activities Is confidential and will be used only in connection with Mr. Walsh's otudy to 1dentify the service system for enotionally disturbed deaf children. I understand that my child's name will not appear in the published study.

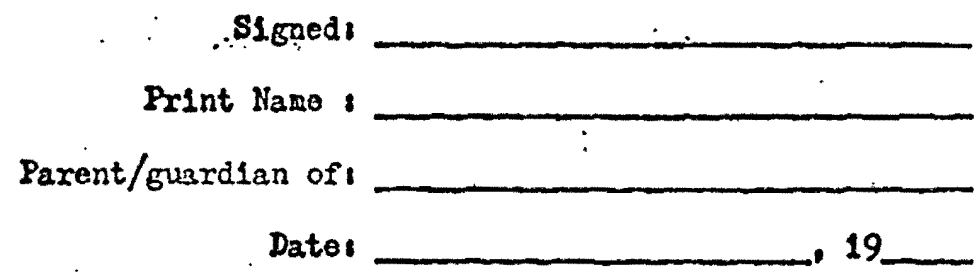

PLEASS RETURN IN THE ENYELOPE PROVIDED

or ma1l tor

Patrick F. Walsh

c/o Reglonal Facility for the Deaf

7910 S.L. Market Street

Portland, Orecon 97215 


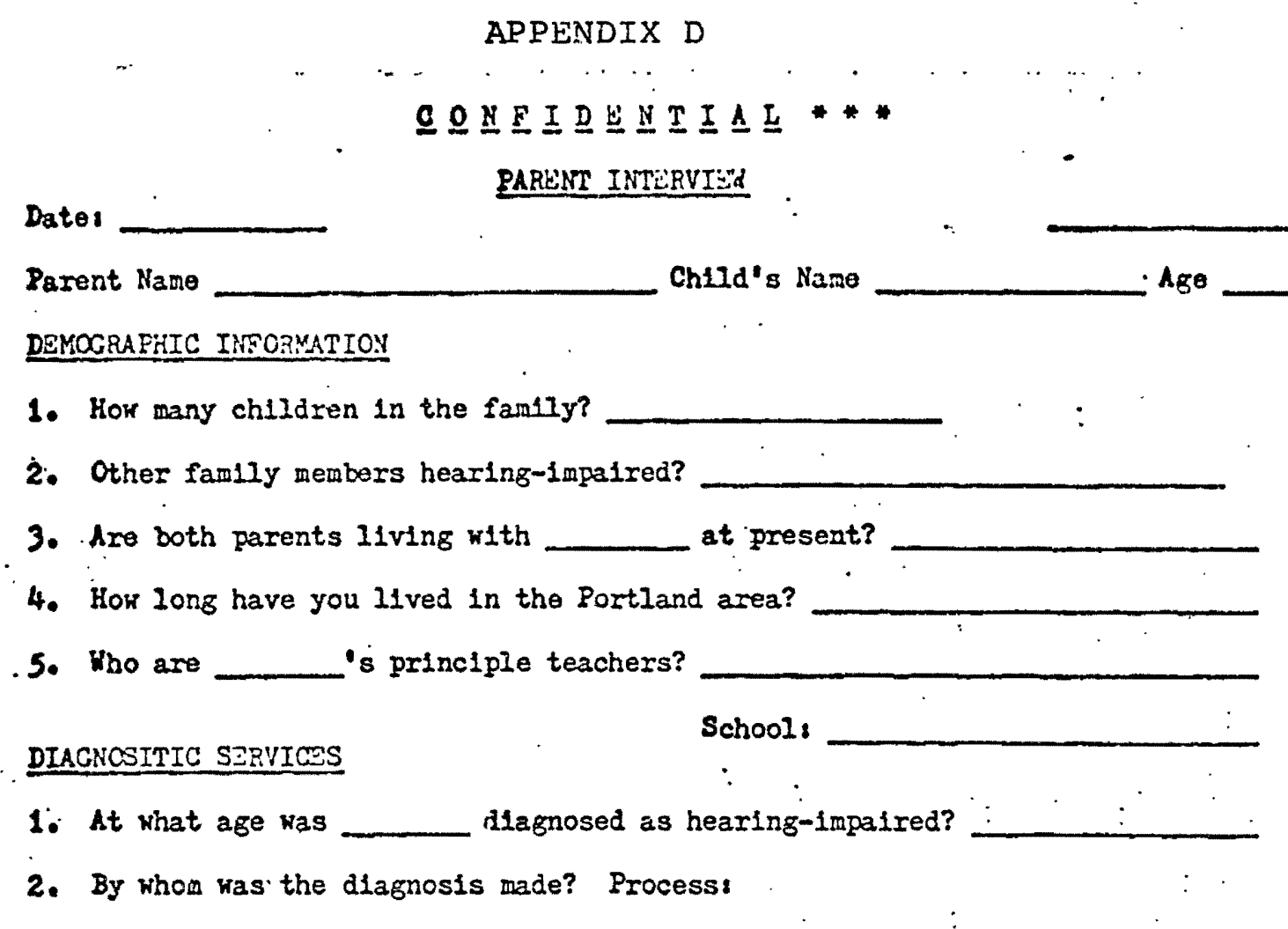

3. Vas someone made avallable at that time to help you understand deafness and make the initial adjustment to your handicapped child? Process:

4. Did you seek out more information about deafness?

Whom did you contact?

How did you find them?

Who helped you? How?

5. Did you look for counseling or other services for your family after the diagnosis?

6. How, did you find services for hearing aids, speech training, pre-school education, etc.?

\section{EDUCATIONAL SERVICUS}

1. At what age did start his/her education?

Where?

How ald you find out about the progran? 
3. How many schools has attended?

Why so many?

Nere changes explained?

4. How often have you been asked to meet with a teacher or staff person of the Reglonal Facllity?.

What about?

Have the conferences helped you?

Helped your chlld?

5. Have you contacted the school about some difflculty? Who?

What about?

Were you satisfied?

6. Is _ recelving vocational training?

Is it needed?

Is it adequate?

7. Does _ have a job? Has he/she in the past?

How did he/she get 1t?

Handle it?

Why not?

Spending money?

8. Are you satisfied with the education is recelving?

PERSONAL SIRVICZS

1. Do you feel you were/are adequately prepared to deal with the adjustment problems of a hearing-1mpaired teenager?

Nere do you get Information, assistance?

Who has helped? 


\section{3

2. Do you feel you have been offered services by the educational system to help you cope with problems in your chlld's adjustment or emotional ilfe?

How?

By whon?

3. What about the whole area of. naturation? Do you see as having any difficult; with relationships, self-awareness, sexual awareness, etc?

Does he/she have information?

Have you talked about 1t?

Do you know $1 f$ any one has?

4. Do you feei is reasonably well adjusted as a teenager?

Specific problems?

Sought help? Whom?

5. Have you as a family ever sought counseling help?

Successful?

Problems with deafness?

6. Have you sought help for emotlonal/behavioral problems with $?$

Where?

How did you find them?

Satisfied? Problems?

7. Has the school ever recominended testing, counseling?

\section{Why?}

Satisfled?

Problems? 
8. Do you now, or have you ever, belonged to a parents group for parents of hearing-impalred children?

Where?

How was 1 t set up?

Horthwhile?

Problems?

9. How many agencles have you been in contact with?

Crippled Chlldrens Div. Portland Ctr. Hearing Sp. Infant Hearing Resource State School for Deaf
Child Development Ctr. Morrison Ctr. Metro Family Services

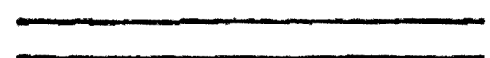

\section{FURURE SERVICES}

1. If you were to have a serious emotional/behavioral problem with to whom rould you go for help?

Why?

2. Do you think etc., In the future? will need special help in education, adjustment, How w1ll you find it? Where?

Who will you ask?

$\therefore$

3. What do you think is the biggest problem facing deaf teenagers in the Portland area?

4. What is the blggest problem faced by parents of deaf teenagers in Portland?

5. How do you think services to deaf teenagers (children) and their parents could be inproved? 


\section{APPENDIX E \\ TEACERR OUESTICMATITE \\ Coiritioiline}

1. Are you a () Resource Room Teacher

( ) Iraveling Teacher

( ) Supervisor, Support Person:

2. How long have you been in the Regional Program for the Deaf?

3. How lons kave you taueht in your present school(s)?

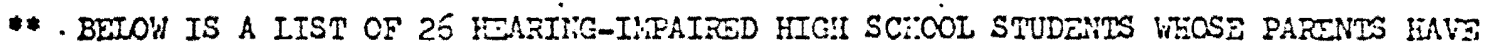

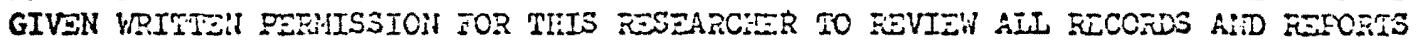

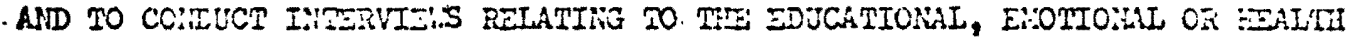
TRYATIEITI OE TEEIR CUILD.

* TEACHETS ARE ASSURED THRT THIS IARORNATION IS FOR TIE EKCLUSIVE USE OF MHIS

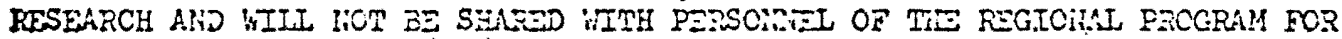

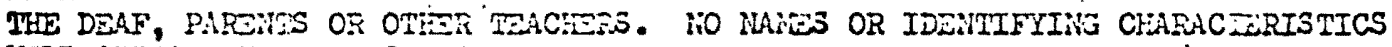
WIIL AFPAAR IN TFE BESIARCH REPCRT.

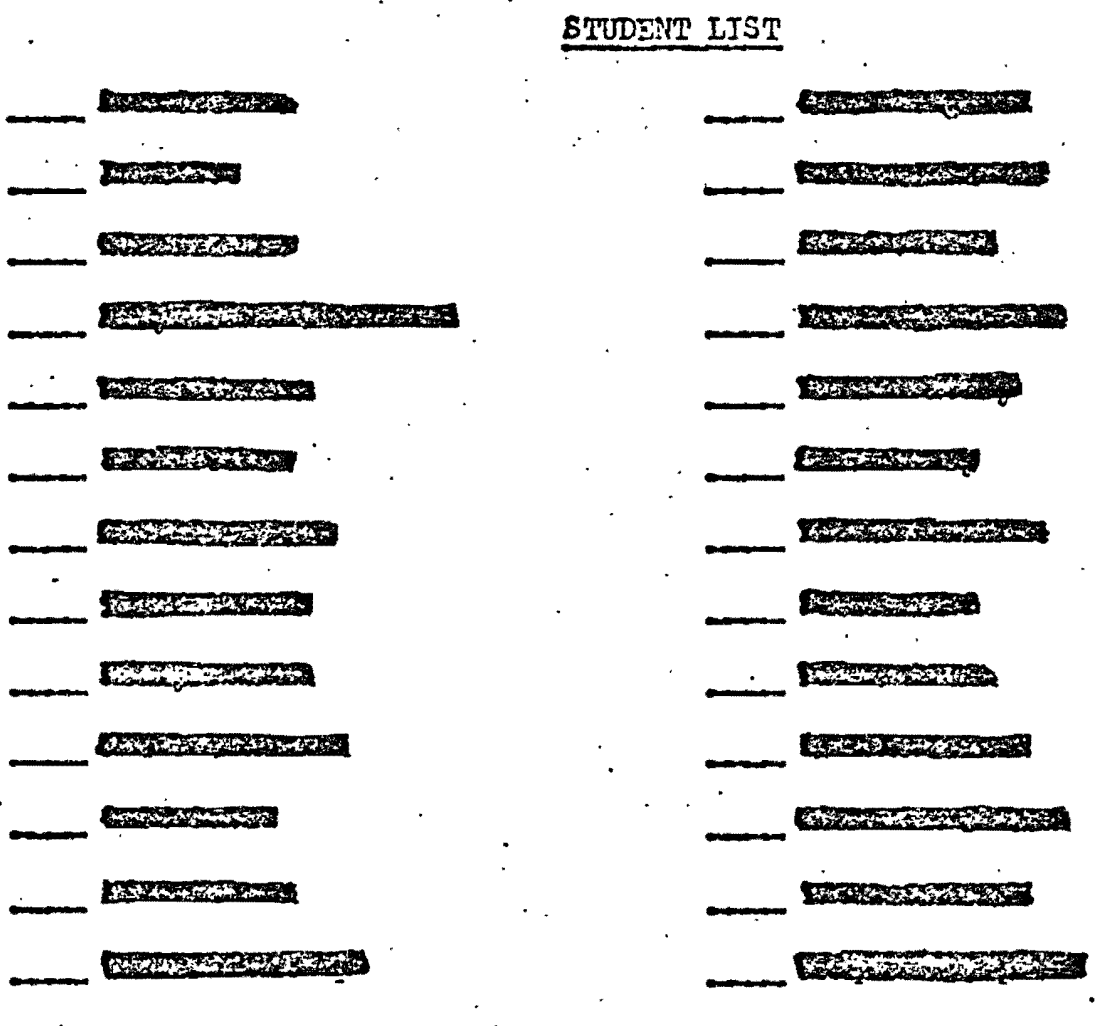

4. On the student list above, please mark an "X" by the names of those students you have taught in the PAST IHEEE YEARS. 


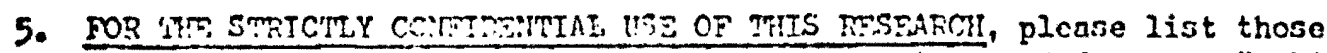
Etudente you merked on the prevolus pale who, injour judeement, "exhibit behavior which requircs a disproncrtionate whare of the teacher's time or requires other special attention."

student $\sharp 1$

Student $1 / 4$

student

Student tos

- Student $\$ 3$

Student

a) Briefly describe the problem of each student.

Student

Student th:

Student

Student fith:

Student

Student

b) Have you tried to intervene in the behavior of any of these students?

\section{() YFS () no}

IF "YES":

c) How did you try to help?

Student 肘:

Student te:

Student 3 :

- student $\not 44:$

Student if:

Student in:

d) Did you refer any of these children, or their parents, to somcone else for furticer help?

(mich students?)

(where did you refer?) 


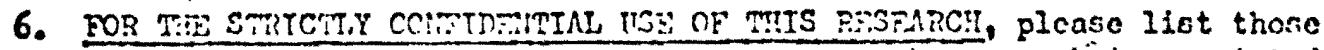
Etudents from tre iret nuge wio are in your ciass, or being aseieted by you, AT THE PFESElTI TIRE.

Student $\ddot{\# 1}$ Student

Student $\ddot{7} 2$ Student 175

Student $\frac{i}{13}$ Student to

a) How often do you Echedule regular parent-teacher conferences?

b) Other than regular conferences, how often and regardins what have you called the parents of:

Student \#1:

Student \#2:

Student $\#$ :

Student \#4:

Student $\frac{\| 1}{\pi 5}$ :

Student

c) How often and regarding what have the student's parents called you?

Student

Student $: 2$ :

Student it3:

Student int

$\therefore$ Student $\$$ :

$\because$ Student

a) thich parents do you feel you have been able to help with information or assistance relatins to the student's benavior? How?

Student \#1:

Student \#2:

Student ir 3 :

Student $\not \|^{4}$ :

Student \#5:

Student \#5: 
7. If you were to identify a scrious emotional or behavioral problem with one of your sturiente (or if the parents were to ask you for holp), who vould you contact? (your conatents are appreciated)

First Contact:

Second Contact:

Tnira Contact:

8. What do you feel is the most serious problem facing hearing-impaired teenagers in the Portland area?

9. In what way do you feel that the provision of social services for hearing-impaired youth and their parents could be improved?

10. Any further comments you may wish to share will be greatiy apprecíated.

THANK YOU VSRY MUCH FOR YOUR TIPE ARD CCOESRAMTON

If clarification or zore information is needed, way I contact you?

( ) 10

() YES .. Name

School

Home phone School Phone 